\title{
Theoretical Design of a Thermosyphon for Efficient Process Heat Removal from Next Generation Nuclear Plant (NGNP) for Production of Hydrogen
}

Piyush Sabharwall

Fred Gunnerson

Akira Tokuhiro

Vivek Utgiker

Kevan Weaver

Steven Sherman

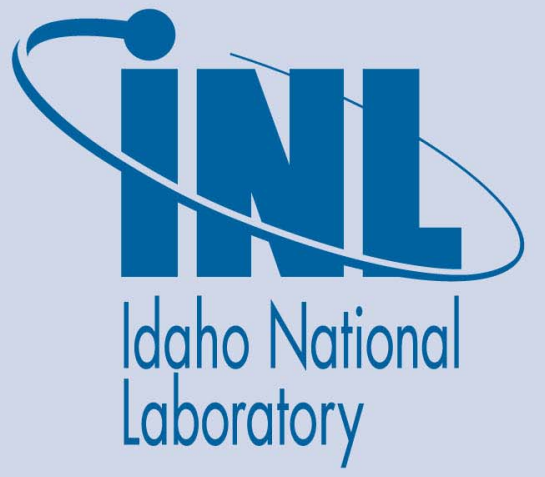

October 2007

The INL is a U.S. Department of Energy National Laboratory operated by Battelle Energy Alliance 
INL/EXT-07-13433

\title{
Theoretical Design of a Thermosyphon for Efficient Process Heat Removal From Next Generation Nuclear Plant (NGNP) for Production of Hydrogen
}

\author{
Piyush Sabharwall \\ Fred Gunnerson \\ Akira Tokuhiro \\ Vivek Utgiker \\ Kevan Weaver \\ Steven Sherman
}

October 2007

\author{
Idaho National Laboratory \\ and \\ University of Idaho \\ Idaho Falls, Idaho 83415
}




\section{Executive Summary}

The work reported here is the preliminary analysis of two-phase Thermosyphon heat transfer performance with various alkali metals. Thermosyphon is a device for transporting heat from one point to another with quite extraordinary properties. Heat transport occurs via evaporation and condensation, and the heat transport fluid is re-circulated by gravitational force. With this mode of heat transfer, the thermosyphon has the capability to transport heat at high rates over appreciable distances, virtually isothermally and without any requirement for external pumping devices.

For process heat, intermediate heat exchangers (IHX) are required to transfer heat from the NGNP to the hydrogen plant in the most efficient way possible. The production of power at higher efficiency using Brayton Cycle, and hydrogen production requires both heat at higher temperatures (up to $1000^{\circ} \mathrm{C}$ ) and high effectiveness compact heat exchangers to transfer heat to either the power or process cycle. The purpose for selecting a compact heat exchanger is to maximize the heat transfer surface area per volume of heat exchanger; this has the benefit of reducing heat exchanger size and heat losses. The IHX design requirements are governed by the allowable temperature drop between the outlet of the NGNP $\left(900^{\circ} \mathrm{C}\right.$, based on the current capabilities of NGNP), and the temperatures in the hydrogen production plant. Spiral Heat Exchangers (SHE's) have superior heat transfer characteristics, and are less susceptible to fouling. Further, heat losses to surroundings are minimized because of its compact configuration. SHEs have never been examined for phase-change heat transfer applications. The research presented provides useful information for thermosyphon design and Spiral Heat Exchanger.

This research will provide valuable data that will be useful in making decisions regarding the heat transfer system between the nuclear reactor and chemical plant. Development of very high temperature reactor technologies for the production of hydrogen and other energy products is high priority research for a successful nuclear future. Idaho National Laboratory (INL) has a premier role to play in the development of these technologies that are integral to the DOE strategic plans for the sustained advances in nuclear energy. 


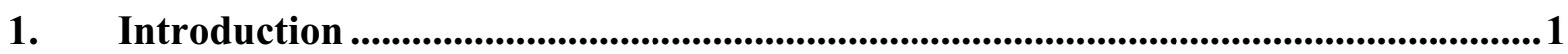

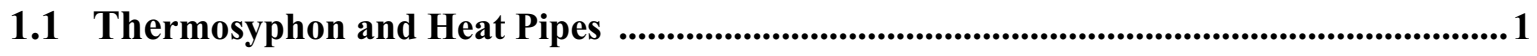

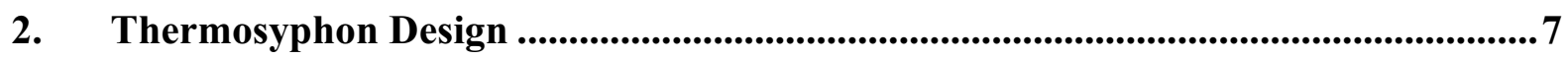

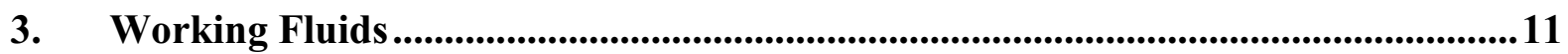

3.1 Mass Flow Rate and Sonic Velocity Analysis ..................................................... 12

3.2 Comparison of Thermosyphon with Convective Loop .........................................15

3.3 Dimensional Analysis of Heat Pipes ................................................................ 18

$4 \quad$ Intermediate Heat Exchanger ..........................................................................................26

4.1 Printed Circuit Heat Exchanger .........................................................................227

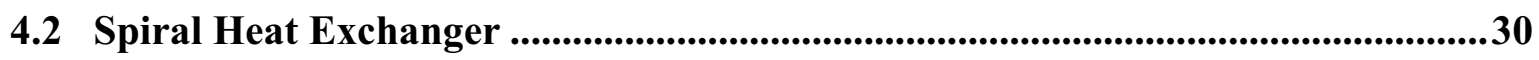

$5 \quad$ High Temperature Materials ....................................................................................35

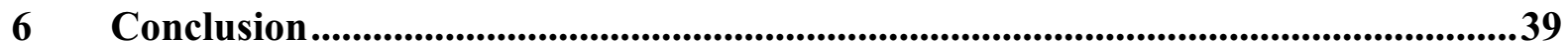

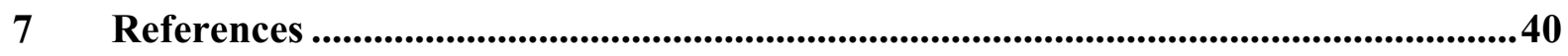




\section{List of Tables}

Table $1 \quad$ Properties of Alkali Metals................................ 14

Table 2 Diameter of the thermosyphon (pipe) for various alkali metals......... 15

Table 3 Variation in Diameter (D) of the thermosyphon with the variation in Sonic Velocity (Vs) for various alkali coolants for 50MW ............. 15

Table $4 \quad$ Enthalpy Gain for two-phase compared to single-phase.............. 17

Table 5 Candidate material for construction of Thermosyphon................ 35

Table $6 \quad$ Candidate material ranking based on ductility.................... 36

Table $7 \quad$ Candidate material ranking based on creep rupture life.............. 36 


\section{List of Figures}

Figure $1 \quad$ The main regions of the Heat Pipe $\ldots \ldots \ldots \ldots \ldots \ldots \ldots \ldots \ldots \ldots \ldots \ldots \ldots \ldots \ldots \ldots \ldots$

Figure 2 The Heat Pipe and Thermosyphon.............................. 2

Figure 3 Sonic Velocity Comparison for Na Vapor.............................. 5

Figure $4 \quad$ Sonic Velocity Comparison for Alkali Metal Vapor........................ 5

Figure $5 \quad$ Schematic of a simple controllable thermosyphon........................ 7

Figure $6 \quad$ Schematic of the Designed Thermosyphon Loop ...................... 9

Figure $7 \quad$ Evaporative spiral heat exchanger..................................... 10

Figure $8 \quad$ Mass Flow Rate of different alkali metals for heat input of 50 MW.......... 14

Figure $9 \quad$ Enthalpy for saturated sodium: liquid and vapor........................ 16

Figure $10 \quad$ Heatric Printed Circuit Heat Exchangers .............................. 27

Figure 11 Assembling sequence of the new PCHE design.......................... 28

Figure 12 Current operating experience of HEATRIC PCHEs..................... 29

Figure $13 \quad$ Schematic of a Spiral Heat Exchanger............................. 30

Figure $14 \quad$ Flow Path for Cold and Hot Fluids................................. 31

Figure $15 \quad$ Modeled Geometry of the Spiral Heat Exchanger (SHE) $\ldots \ldots \ldots \ldots \ldots \ldots \ldots \ldots . . . \ldots 2$ 
Figure 16 Detail Description of the Fluid Flow Motion and Heat Transfer Between

Adjacent elements for the Spiral Heat Exchanger..........................

Figure 17 Benchmarking of the Hotter side of SHE with the Dittus Boelter Correlation...

Figure 18 Benchmarking of the Cold side of SHE with the Dittus Boelter Correlation...

Figure 19 Comparison of ASME allowable stress for high temperature alloys...........

Figure 20 Thermal expansion for the various alloys at elevated temperatures...........

Figure 21 Thermal conductivity for the various alloys at elevated temperatures.........

Figure 22

Comparison of Nitriding Resistance.

38 


\section{Nomenclature}

A Cross-Sectional Flow Area $\left[\mathrm{m}^{2}\right]$

C Heat capacity rate $\left[\mathrm{W} \mathrm{K}^{-1}\right]$

El Elongation [\%]

$\Delta \mathrm{H} \quad$ Specific Enthalpy Change of the Transport Fluid $\left[\mathrm{kJkg}^{-1}\right]$

$\mathrm{M} \quad$ Mol wt $\left[\mathrm{Kg} \mathrm{kmole}^{-1}\right]$

$m^{\prime} \quad$ Mass Flow Rate $\left[\mathrm{kgs}^{-1}\right]$

Q1 Axial Heat Flow Rate [W]

$Q^{\prime \prime} \quad$ Rate of thermal energy transport per unit flow area $\left[\mathrm{kJm}^{-2} \mathrm{~s}^{-1}\right]$

q Heat flow from the channel $\left[\mathrm{W} \mathrm{K}^{-1} \mathrm{rad}^{-1}\right]$

$\mathrm{R} \quad$ Universal Gas Constant $\left[\mathrm{J} \mathrm{kmole}^{-1} \mathrm{~K}^{-1}\right]$

$\mathrm{S}^{898}$ Design Stress at $898^{\circ} \mathrm{C}[\mathrm{MPa}]$

$\mathrm{T} \quad$ Operating Temperature $[\mathrm{K}]$

$\mathrm{t} \quad$ Dimensionless Temperature; $\frac{\mathrm{t}^{\prime}-\mathrm{t}_{\mathrm{c}, \mathrm{i}}^{\prime}}{\mathrm{t}_{\mathrm{h}, \mathrm{i}}^{\prime}-\mathrm{t}_{\mathrm{c}, \mathrm{i}}^{\prime}}$

$\mathrm{V} \quad$ Average Flow Velocity $\left[\mathrm{ms}^{-1}\right]$

Vs Sonic Velocity $\left[\mathrm{ms}^{-1}\right]$

$\bar{V} \quad$ Average vapor velocity $\left[\mathrm{m} \mathrm{s}^{-1}\right]$

z Characteristic dimension [m]

Greek Symbols

$\beta_{\mathrm{S}} \quad$ Vapor Adiabatic Compressibility $\left[\mathrm{MPa}^{-1}\right]$

$\rho \quad$ Density $\left[\mathrm{Kg} \mathrm{m}^{-3}\right]$ 
$\lambda \quad$ Heat of Vaporization $\left[\mathrm{Jkg}^{-1}\right]$

$\gamma \quad$ Ratio of Specific Heat

$\sigma \quad$ Surface Tension $\left[\mathrm{N} \mathrm{m}^{-1}\right]$

$\varphi \quad$ Differential Angle [Radians]

Subscripts

b.p Boiling Point

C Cold Fluid

i,j,r Spiral Position

H Hot Fluid

L Liquid

m.p Melting Point

n Element Position in Computation

v Vapor

Dimensionless Numbers

$\mathrm{Nu} \quad$ Nusselt Number

Pr Prandtl Number

Re Reynolds Number

We Weber Number 


\section{Introduction}

The application of nuclear power plants as a source of process heat has received national interest because of better economics without greenhouse gases. The Next Generation Nuclear Plant (NGNP) will most likely be producing electricity and process heat, used for hydrogen production. The process heat applicability is not restricted to hydrogen production, but also various other technologies such as extraction of iron ore, coal gasification and liquefactions, etc. For process heat, a thermal device is needed in order to transfer the thermal energy from the NGNP to the hydrogen plant in the most efficient way possible. Heat pipes have been recognized for several years as very effective heat transport device. They transport large amount of heat with small temperature gradients independent of gravity effects. Heat pipe is a device of very high thermal conductance, which came into existence in early 1942 [Gaugler, R.S, 1944], but the important features of a heat pipe were not realized until 1960s.

\subsection{Thermosyphon and Heat Pipes}

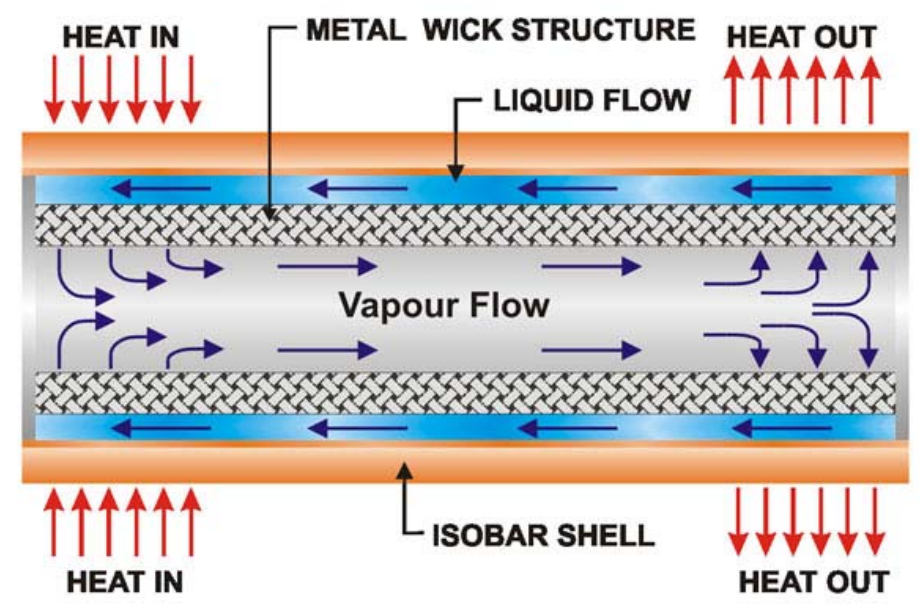

Figure 1. The main regions of the Heat Pipe [www.acrolab.com]

Heat pipe, as can be seen in Figure 1 is essentially a constant temperature device. It consists of a closed container in which vaporization and condensation of a fluid takes place. The choice of a fluid depends on the temperature range in which the heat pipe will be used. Heat is applied to one end of the heat pipe (evaporator), the local temperature is raised leading to evaporation of the working fluid. Because of the saturation conditions this temperature difference results in a difference in vapor pressure which in turn causes vapor to flow from the heated section to the cold section of the pipe (condenser). The rate of vaporization is equal with heat absorbed in the form of latent heat of evaporation. The resulting condensate is returned to the heated end (evaporator) of the container by the action of capillary forces in the liquid layer which is contained in a wick lining the inside of 
the cavity. A typical wick might consist of layers of metal screen or some porous metallic structure. A wick is used in the heat pipes to return the working fluid from the condenser to the evaporator.

Wicking material is used only in region to facilitate the path of the vapor to pipe. Typically a good wicking material maximizes the movement of the fluid, has uniform porosity, have very small pores such that the wick can generate a large capillary pressure, be resistant to degradation by temperature, and not react or degrade chemically with the working fluid. Heat pipes can have a number of different geometric configurations, these configurations include cylindrical, spherical, square or any other geometry such that inner volume of the heat pipe forms a channel from the evaporator section to the condenser section. Metals used to fabricate the heat pipes should be compatible with the working fluid as well with the external media in contact with the evaporator and the condenser. The outermost shell of the heat pipe is referred as the container. The container encloses the functioning parts of the heat pipe and provides the structural rigidity. The liquid flow takes place in a porous material usually referred to as wick. The interior space of the heat pipe is called the vapor core, which provides the passage for the vapor flow. Heat Pipes have been used extensively in a variety of energy storage system (Chemical Reactors, Space Craft temperature equalization). Heat pipes are suited to thermal storage systems, in particular, in the role of heat delivery and removal, because of their high effective thermal conductivity and their passive operation.

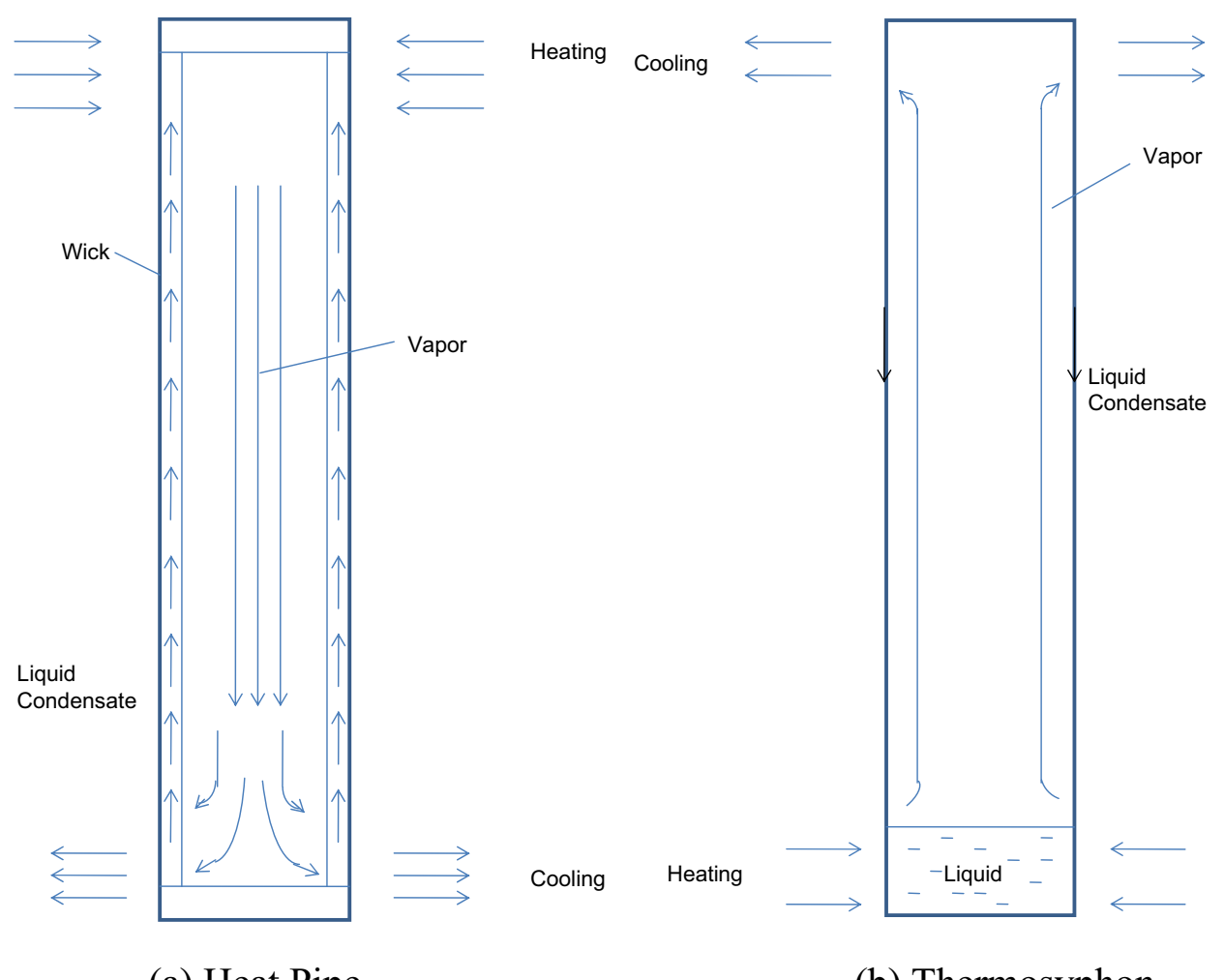

(a) Heat Pipe

(b) Thermosyphon

Figure 2. The Heat Pipe and Thermosyphon (Reay, D. and Kew, P., 2006) 
The heat pipe, as can be seen from Figure 2 is similar to thermosyphon in some respects, the main difference is the mechanism in which the fluid is returned from the condenser to the evaporator section, as for a heat pipe the mechanism is by capillary action. The operation of a heat pipe relies upon the capillary head within the wick which is sufficient to overcome the pressure drops associated with the liquid and vapor flow and the gravitational head. In a thermosyphon the condensate is further returned to the hot end by gravity. Since the latent heat of evaporation is large, considerable amount of heat can be transported with a very small temperature difference from end to end. The main limitation of the thermosyphon is that in order for the condensate to be returned to the evaporator region by gravitational force, the evaporator region has to be located at the lowest point in the system. In the case of a heat pipe we have a wick which is constructed from few layers of fine gauze and is fixed to the inside surface and the capillary forces return the condensate to the evaporator. The heat pipe has more flexibility in terms of location of the evaporator region and if the evaporator region does happen to be in the lowest position, the gravitational forces will assist the capillary forces.

Although the heat pipe is a very high thermal conductance device it possesses heat transfer limitations governed by principles of heat transfer and fluid mechanics. Depending upon the condition the heat transport may be limited by one of the following:

\section{Capillary pumping limit}

Fluid circulation in a heat pipe is maintained by capillary forces which develop in the wick structure at the liquid vapor interface. These forces balance the pressure losses arising from the flow of the liquid and the vapor phases. When the flow rates are such that the capillary forces no longer exceed the pressure losses, the capillary pumping limit is reached. The attainment of this limit leads to dryout of the evaporator wick resulting in failure of heat pipe operation.

\section{Sonic limit (choking) of vapor flow}

The vapor velocity increases steadily along the length of the evaporator section due to the progressively increasing vapor flow and reaches a maximum at the evaporator exit. The maximum vapor velocity which can exist at the evaporator exit corresponds to Mach 1. This choked flow condition is a fundamental limit on the axial vapor flow in a heat pipe. The axial heat flux for the sonic limit is obtained by calculating the mass flow rate at Mach 1 i.e. 
$\frac{\mathrm{Q}_{1}}{\mathrm{~A}_{\mathrm{V}}}=\rho_{\mathrm{V}} \lambda \mathrm{V}_{\mathrm{S}}$

where, the sonic velocity $V_{S}$ is given by the familiar equation:

$V_{S}=\sqrt{\frac{\gamma R T}{M}} \quad$ (Golden, G.H., and Tokar, T.V, 1967)

At, the sonic limit, the mass flow rate per unit area and the corresponding axial heat flux depend only on the properties of the working fluid and in turn the operating temperature. The speed of sound in the vapor sodium is calculated from the vapor adiabatic compressibility $\left(\beta_{\mathrm{s}}\right)$ and the vapor density $\left(\rho_{\mathrm{v}}\right)$ using the thermodynamic relation:

$\mathrm{V}_{\mathrm{s}}=\frac{1}{\sqrt{\rho_{\mathrm{v}} \beta_{\mathrm{s}}}} \quad$ (Fink, J.K., and Leibowitz, L, 1995)

In Figure 3, Na vapor sonic velocity is compared to the limited data which is predicted by theory and a good agreement was found, which made us believe in the data for the other alkali metals. The sonic velocity of the different alkali metals have been compared, as can be seen from Figure 4. 


\section{Sonic Velocity for Na Vapor Comparison}

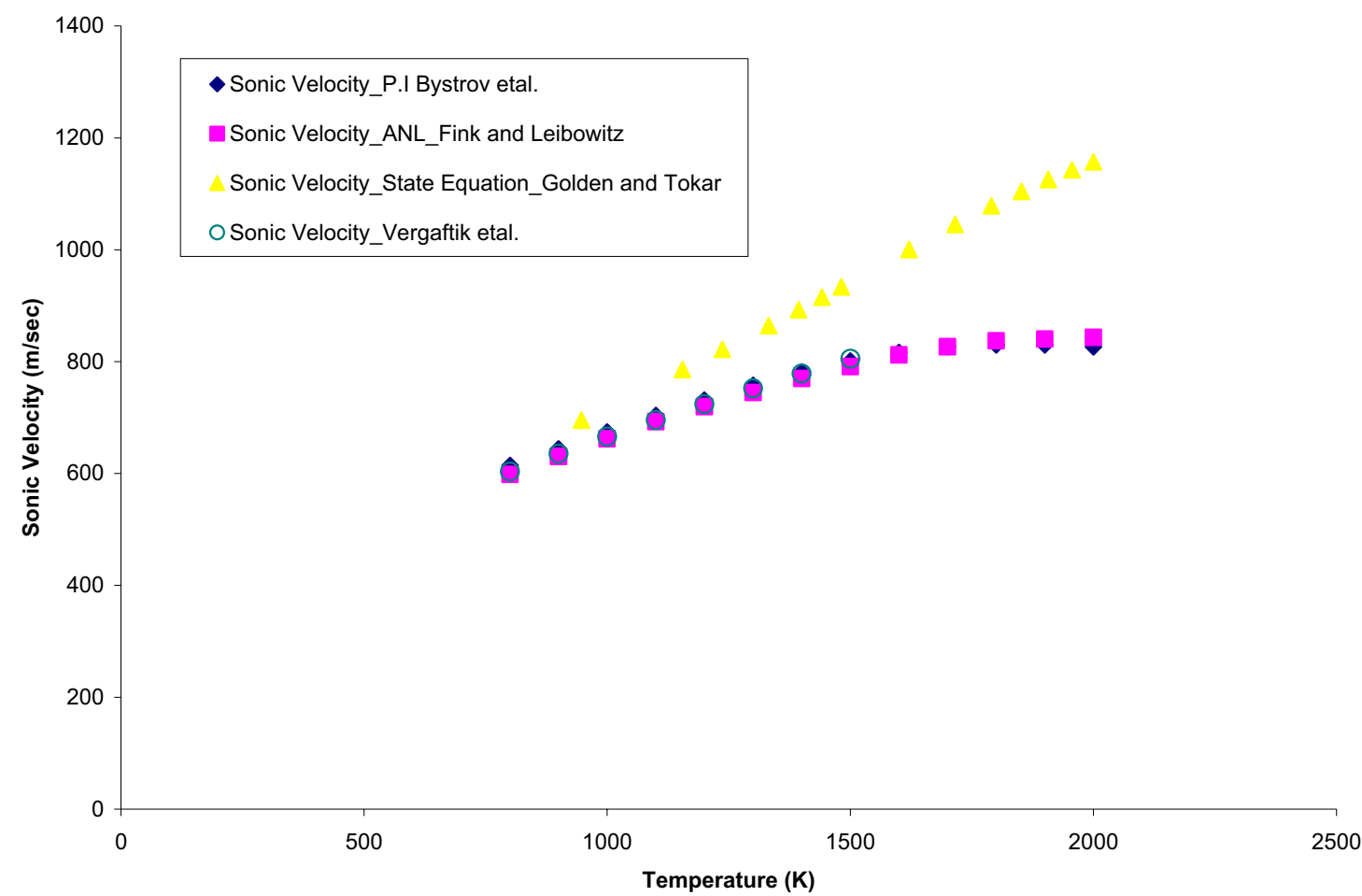

Figure 3. Sonic Velocity for $\mathrm{Na}$ Vapor

\section{Sonic Velocities of Alkali Metals (Li, Na, K, Cs)}

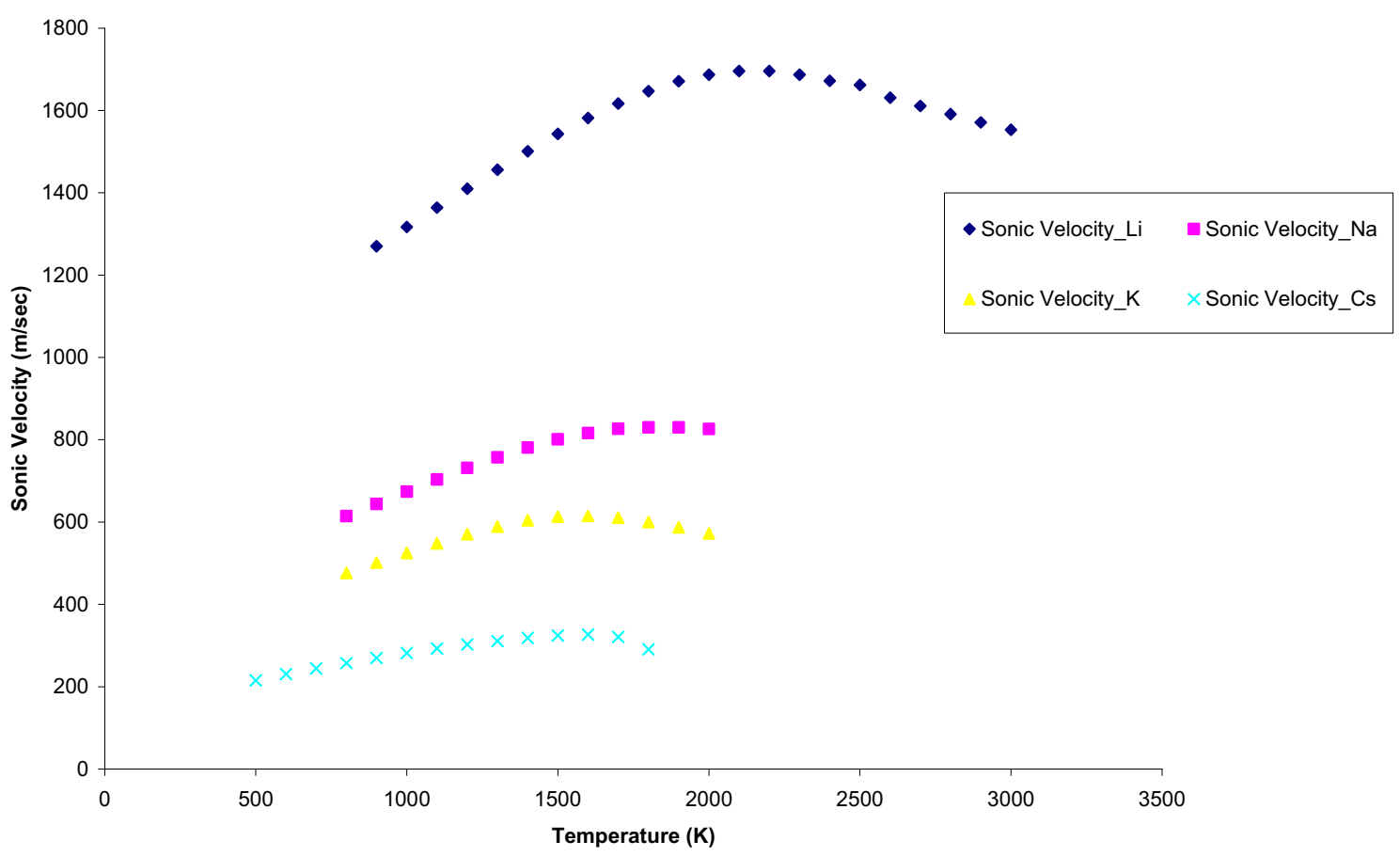

Figure 4. Sonic Velocity for Alkali Metal Vapor [Bystrov, P.I., et al., 1990] 


\section{Entrainment limit}

The entrainment limit is also a characteristic of high axial vapor velocities as the sonic limit. Since liquid and vapor are in direct contact along the heat pipe, separated only by the meniscus at the wick, a mutual shear force exists between them. At low relative velocities, this shear force will only add to the viscous drag in both phases. The vapor velocity is usually much higher than that of the liquid, the effects will be most noticeable in the liquid phase. If the relative velocity becomes too high, the interface becomes unstable and liquid droplets are torn from the wick and entrained in the vapor.

Entrainment may be modeled by the Weber number [Brennan, P.J., 1979], which is a ratio of the inertial forces in the vapor to the tension forces in the liquid surface. The Weber number is defined as:

$$
\mathrm{We}=\frac{\rho_{\mathrm{V}} \overline{\mathrm{V}}^{2}}{\sigma / \mathrm{z}}
$$

A Weber number is the ratio between inertial vapor forces and liquid surface tension forces. At the interface between the wick surface and the vapor, the vapor exerts shear force on the liquid in the wick and its action will be to entrain liquid droplets, this action is resisted by the surface tension in the liquid. Therefore, Weber number of unity is generally believed to indicate the onset of entrainment. There is some uncertainty as to the proper choice of the characteristic dimension z. The phenomenon of entrainment reduces the amount of liquid pumped back to the evaporator by prematurely returning it to the condenser and therein limits the amount of heat flow through the heat pipe.

The operating characteristics of a thermosyphon have been the subject of extensive studies in the development of thermosyphon technology. However, most of these studies have only focused on the thermal and hydrodynamic behaviors in certain portions, such as evaporator, condenser, etc. Very less attention has been given to the overall performance by considering the thermosyphon pipe as a whole. In this study, the overall theoretical performance of a thermosyphon using different liquid metal such as $\mathrm{Na}, \mathrm{Li}, \mathrm{Cs}$ and $\mathrm{K}$ are analyzed so that the Next Generation Nuclear Power Plant (NGNP) is able to transfer the required thermal energy for the production of hydrogen in most efficient way. 


\section{Thermosyphon Design}

A Thermosyphon is a two phase heat transfer device to transfer the process heat from the NGNP plant to the hydrogen plant. It can transfer heat successfully for distances up to several meters in the gravity field. In contrast to single-phase forced convective heat transfer via 'pumping a fluid', a thermosyphon (also called a wickless heat pipe) transfers latent heat through the vaporization / condensing process. It utilizes a highly efficient, controllable, and nearly isothermal vapor heat transfer process with gravity liquid return and requires no pumps or compressors. It can deliver heat to the industrial plant with essentially no temperature loss. A thermosyphon, conceptually illustrated in Figure 5, is a 'wickless heat pipe' with a separate liquid return line. It is an intriguing option to traditional pumped fluid heat transfer. Both rely on fluid (liquid, gas, vapor) convection to transport thermal energy inside pipes and both require in-line, high-temperature heat exchangers. Single- Phase gas loops require compressors and liquid loops require pumps; both are problematic at highesttemperature industrial scale.

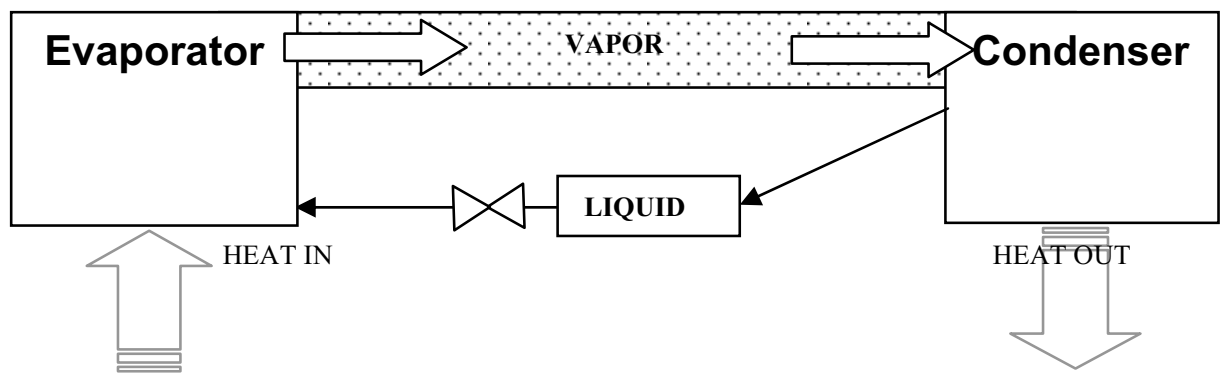

Figure 5. Schematic of a simple controllable thermosvphon

The inclined thermosyphon, as shown in Figure 6 requires no pump and its inherent simplicity promises enhanced reliability with economic advantage in both capital and maintenance. Heat is transported by saturated or superheated vapor expanded from an evaporative heat exchanger, through a long pipe to a condensation heat exchanger. Liquid condensate returns to the evaporator assisted by gravity through a separate liquid return line with a liquid return control valve. A simple loop is shown; at startup there is enough coolant to sufficiently fill the condenser, the evaporator and the liquid storage reservoir. When the thermosyphon is started by applying power (process heat from NGNP) to the evaporator, the working fluid is evaporated and the latent heat of vaporization is transported through the heat pipe to the condenser region. In the design discussed here the condensate returns to the evaporator region through a liquid bypass line containing a liquid storage reservoir and a control valve as shown in Figure 6. The storage reservoir is incorporated with electric resistance heating in order to melt the working fluid, which is very useful when we have to restart the heat pipe after a long shutdown period. Liquid from the storage reservoir passes into the thermosyphon system through a check valve, 
which if needed, plays a salient role in shutting of the thermosyphon. The fluid is evaporated at a vapor pressure corresponding to the saturation pressure of the fluid at the instantaneous temperature of the heat pipe in the evaporator. The condenser region of the system is at lower temperature than the vapor phase region, causing the fluid to condense and release its latent heat of vaporization to the walls of the condensing region. Flow in the condenser region initially consists of high velocity vapor, as the vapor condenses, into slugs of liquid separated by bubbles of vapor and finally gets stored in the storage tank if the check valve is closed. The pressure exerted by the flow of the vapor from the vapor phase flow causes the vapor to flow to the condenser region and the condensate to flow to the evaporator region. In order for the thermosyphon device to be completely disabled from heat transfer, the check valve is placed in a fully closed position wherein all the working fluid is collected as liquid in the liquid storage reservoir and the condensing evaporating cycle is terminated. When it is desired to resume the thermosyphon action, the check valve is opened to allow the liquid to flow into evaporator region of the system. Flow rate of the working fluid governs the rate of evaporation and the subsequent rate of heat transfer. Thus the rate of thermal energy exchange can be regulated over a spectrum of conditions from off to fully on. 


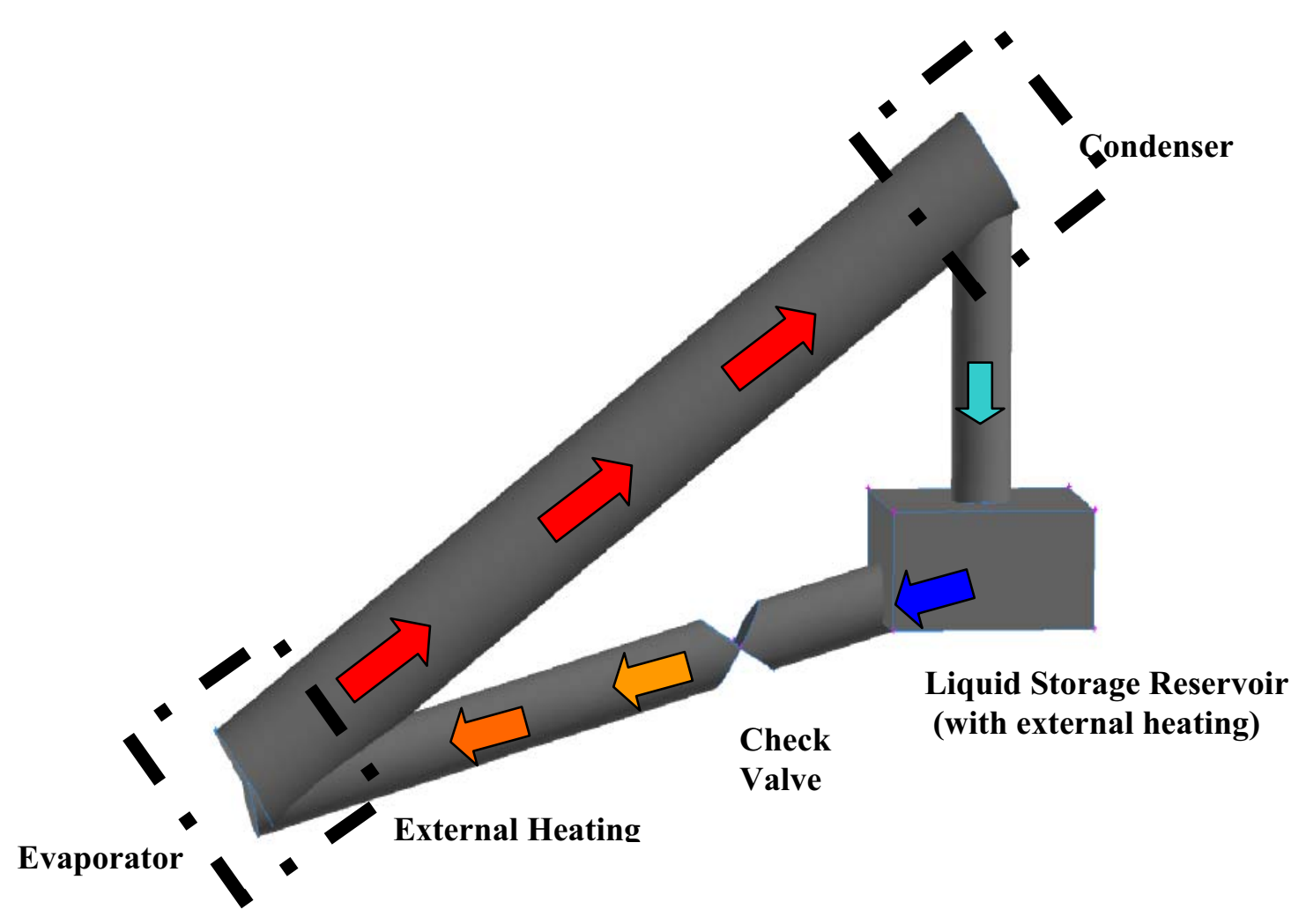

Figure 6. Schematic of Thermosyphon Loop

The color of arrows in Figure 6 represents the flow \& temperature of the flowing fluid in the thermosyphon. As the evaporator region will be at hottest temperature, the arrow has been shown by red and since the heat transfer in the heat pipe is adiabatic and isothermal, there is hardly any temperature difference between both sections of the thermosyphon. After going through the condenser section there is a temperature drop in the fluid which is shown by the sky blue color and further reduction of temperature in the compensation chamber (reservoir) has been shown by dark blue color. The reservoir and the connecting pipe to the evaporator is set up with external heating (orange color), which will be needed if we have to start up the thermosyphon loop after a shutdown period. The evaporator and condenser heat exchangers are located at the NGNP and at the industrial facility, respectively. The heat exchangers could be phase-change spiral heat exchangers. The specific volume change from convective evaporation and condensation is well accommodated by the spiral design as shown in Figure 7. Liquid flows into the 'eye' of the spiral, gains heat, and vapor exits from the spiral 'horn' for transport to the distant condenser at the industrial end user. 


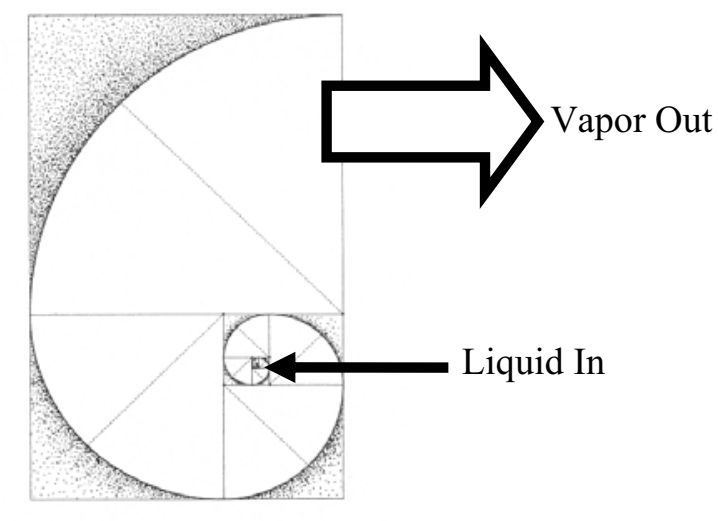

Figure 7. Evaporative spiral heat exchanger

Since the sink temperature is constant (i.e. $850^{\circ} \mathrm{C}$ at the inlet of hydrogen plant) the decrease in the evaporator temperature is synonymous with the increasing thermosyphon conductance. As with any thermosyphon, the overall conductance is determined by the evaporator and condenser conductances:

$$
\frac{1}{\text { Conductance }_{\text {overall }}}=\frac{1}{\text { Conductance }_{\text {evaporator }}}+\frac{1}{\text { Conductance }_{\text {condenser }}}
$$

The evaporator conductance is assumed to be constant; thus the increase in overall conductance with the increasing power must be the result of increasing condenser conductance. This is accomplished by gradually displacing more liquid from the condenser.

As the power is increased, more and more condenser area becomes active and the overall conductance of the thermosyphon continues to increase. In this mode of operation, it behaves as a variable conductance heat pipe (VCHP). In our analysis we have assumed at 50MW the thermosyphon behaves like a fixed conductance heat pipe i.e. further increase in the conductance is no longer possible.

START-UP: During the start-up scenario, storage tank is independently electrically heated in order to melt solid alkali metal and then is drained to the evaporator, which subsequently transfers the thermal energy to the condenser region.

SHUT DOWN: In order to shut off the thermosyphon the check valve (unidirectional flow) connected between the storage tank and the evaporator is turned off completely i.e. no flow of the coolant. 


\section{Working Fluid Selection}

The coolants that are being considered for the thermosyphon are as follows:

\section{Lithium ( m.p $179^{\circ} \mathrm{C}$; b.p. $1317^{\circ} \mathrm{C}$ )}

Lithium (Li) is the rarest alkali metal, with the exception of cesium. It is the least dense of the normally solid elements, and it is the least typical and most reactive of the alkali metals. Lithium is harder than other alkali metals but is softer than lead. Lithium offers interesting characteristics as a heat-transfer fluid in hightemperature systems. It is the lightest metal and has a comparatively high conductivity, high specific heat, a high boiling point, and a moderately low melting point. Its low density permits high fluid velocities without encountering high pressure drop in the system. At high temperatures lithium reacts with carbon to form acetylides that hydrolyze to give acetylene which may be explosively flammable. Near the melting point, lithium may ignite in air and burn with an intense cloud of white smoke, the principal product is the monoxide $\mathrm{Li}_{2} \mathrm{O}$. Lithium can not be melted in glass or in the usual laboratory ceramics because it severely attacks them. The noble gases, thoroughly freed of oxygen, water, and nitrogen, must be used to prevent contact of lithium with the atmosphere. Stainless steel has been considered unsuitable for handling liquid lithium at high temperatures; liquid lithium attacks stainless steel and dissolves nickel [Lyon, R.N., et al., 1952]. Most likely the material used for the construction of the thermosyphon will be an alloy of nickel, because of its durability and sustainability at high temperatures. In our analysis Li is discarded as a coolant as its boiling point is higher than the operational temperature $\left(1000^{\circ} \mathrm{C}\right)$ of the thermosyphon.

\section{Sodium ( m.p $97.8^{\circ} \mathrm{C}$; b.p. $883^{\circ} \mathrm{C}$ )}

Solid Sodium $(\mathrm{Na})$ is relatively soft, silvery-white metal. Molten sodium is a silvery-white metal whose outstanding characteristic is its reactivity with most gases or liquids other than the noble gases and nitrogen. Solid Na tarnishes almost immediately when exposed to air, owing to the formation of a film of oxide. Molten sodium burns readily in the normal atmosphere to form dense flumes of sodium monoxide. With pure oxygen, molten sodium burns with a yellow flame, forming a mixture of sodium monoxide and sodium peroxide. The reaction of sodium with water is energetic and possibly explosively rapid if the contact interfaces are large. Sodium and heavier alkali metals do not react with nitrogen. Sodium reacts vigorously with halogens, acidic oxides, and mercury, and alloys with lead, tin, zinc, and bismuth. Nitrogen, argon, and helium do not react with sodium, and these gases should be used to prevent the atmosphere from contacting sodium, either in the solid or 
the liquid state. Sodium does not react with glass at low temperatures, i.e., less than $300^{\circ} \mathrm{C}$; above this temperature pyrex glass is rapidly attacked [Lyon, R.N., et al., 1952].

\section{Potassium ( m.p $63.7^{\circ} \mathrm{C}$; b.p. $760{ }^{\circ} \mathrm{C}$ )}

Potassium (K) reacts similarly to sodium with the exception that, in general, potassium is more reactive. When exposed to oxygen, potassium oxidizes to superoxide $\mathrm{KO}_{2}$. The superoxide of potassium will form at low temperatures, but the cause of explosions with combinations of potassium superoxide and potassium metal is not completely understood. When potassium reacts directly with carbon monoxide an explosive carbonyl is formed unlike in sodium [Lyon, R.N., et al., 1952]. Whereas lithium and sodium react only superficially with liquid bromine, potassium detonates when brought into contact with it. Ordinary potassium is the lightest naturally occurring radioactive element; it contains 0.011 per cent of beta or gamma emitting ${ }_{19} \mathrm{~K}^{40}$ with a half life of $2.4 \times 10^{8}$ years.

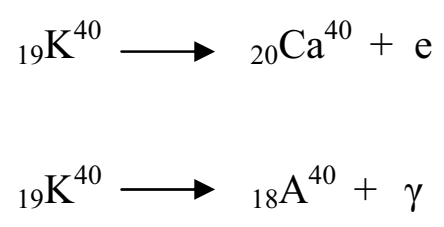

\section{Cesium ( m.p $28.5^{\circ} \mathrm{C}$; b.p. $705^{\circ} \mathrm{C}$ )}

Cesium (Cs), is silvery-white in appearance and is very soft and ductile. It is the most electropositive of all the metals and has a high specific gravity. It catches fire in dry air and in general reacts the same as the other alkali metals. Cs absorbs carbon monoxide at room temperature [Lyon, R.N., et al., 1952].

\subsection{Mass Flow Rate and Sonic Velocity Analysis}

A thermosyphon can transport comparable amounts of thermal energy as a single-phase convective loop, within the same diameter pipe. The ideal rate of convective heat transport through a pipe without losses; modeled in terms of enthalpy can be written as:

$$
Q^{\prime \prime}=\Delta \mathrm{H} \rho \mathrm{V}=\frac{\dot{\mathrm{m}}}{\mathrm{A}} \Delta \mathrm{H}
$$


where $Q^{\prime \prime}$ is the rate of thermal energy transport per unit flow area $\left(\mathrm{kJ} / \mathrm{m}^{2} \mathrm{~s}\right), \Delta \mathrm{H}$ is the change of the specific enthalpy of the transport fluid $(\mathrm{kJ} / \mathrm{kg}), \mathrm{V}$ is the average flow velocity $(\mathrm{m} / \mathrm{s}), m^{\prime}$ is the mass flow rate $(\mathrm{kg} / \mathrm{s}), \rho$ is density $\left(\mathrm{kg} / \mathrm{m}^{3}\right)$, and $\mathrm{A}$ is the cross-sectional flow area $\left(\mathrm{m}^{2}\right)$.

Two-phase heat transfer by a thermosyphon has the advantage of high enthalpy transport that includes the sensible heat of the liquid, the latent heat of vaporization, and possible vapor superheat. In contrast, singlephase forced convection transports only the sensible heat of the fluid. Additionally, vapor-phase velocities within a thermosyphon can be much greater than single-phase liquid velocities within a forced convective loop.

$$
\begin{aligned}
& Q^{\prime \prime}=\frac{\dot{\mathrm{m}}}{\mathrm{A}} C_{P, L} \Delta T_{L} \quad \text { (single phase) } \\
& Q^{\prime \prime}=\frac{\dot{\mathrm{m}}}{\mathrm{A}}(\underbrace{\mathrm{C}_{\mathrm{P}} \Delta \mathrm{T}_{\text {liquid }}}_{\text {Sensible heat of the liquid }}+\underbrace{\mathrm{h}_{\mathrm{fg}}}_{\text {Latent heat of vaporization }}+\underbrace{\mathrm{C}_{\mathrm{P}} \Delta \mathrm{T}_{\text {Vapor }}}_{\text {Vapor Superheat }})
\end{aligned}
$$

In our case the $Q^{\prime \prime}$ is assumed to be $50 \mathrm{MW}$ (process heat from NGNP for hydrogen production), and the mass flow rate for all the different alkali metal is obtained from the following expression (Figure 8):

$$
\dot{\mathrm{m}}=\frac{Q^{\prime \prime}}{\mathrm{C}_{\mathrm{P}} \Delta \mathrm{T}_{\text {liquid }}+\mathrm{h}_{\mathrm{fg}}+\mathrm{C}_{\mathrm{P}} \Delta \mathrm{T}_{\text {Vapor }}}
$$

where,

$$
\begin{aligned}
& \Delta \mathrm{T}_{\text {Liquid }}=\mathrm{T}_{\text {melt }}-\mathrm{T}_{\text {boil }} \\
& \Delta \mathrm{T}_{\text {Vapor }}=\mathrm{T}_{\text {operating temperature }}-\mathrm{T}_{\text {boil }} \quad \text { (Operating temperature is assumed at } 1000^{\circ} \mathrm{C} \text { ) }
\end{aligned}
$$


Table1. Properties of Alkali Metals

\begin{tabular}{|c|c|c|c|}
\hline Alkali Metal & $\mathbf{T}_{\text {melting }}(\mathbf{K})$ & $\mathbf{T}_{\text {boiling }}(\mathbf{K})$ & $\mathbf{h}_{\mathbf{f g}}(\mathbf{K J} / \mathbf{K g})$ \\
\hline $\mathrm{Li}$ & 452 & 1590 & 19594 \\
\hline $\mathrm{Na}$ & 370.8 & 1156 & 4207 \\
\hline $\mathrm{K}$ & 336.7 & 1033 & 2076 \\
\hline $\mathrm{Cs}$ & 301.5 & 978 & 611 \\
\hline
\end{tabular}

From Table 1, Li can be discarded as the potential coolant as it does not even boil until $1317^{\circ} \mathrm{C}$, and we intend to operate the thermosyphon at $1000^{\circ} \mathrm{C}$. So based on its much higher boiling point than the operating temperature of the thermosyphon we will not select $\mathrm{Li}$ as the potential coolant for the thermosyphon. Figure 8 shows the mass flow rate of the alkali metals for heat supply of $50 \mathrm{MW}$, respectively.

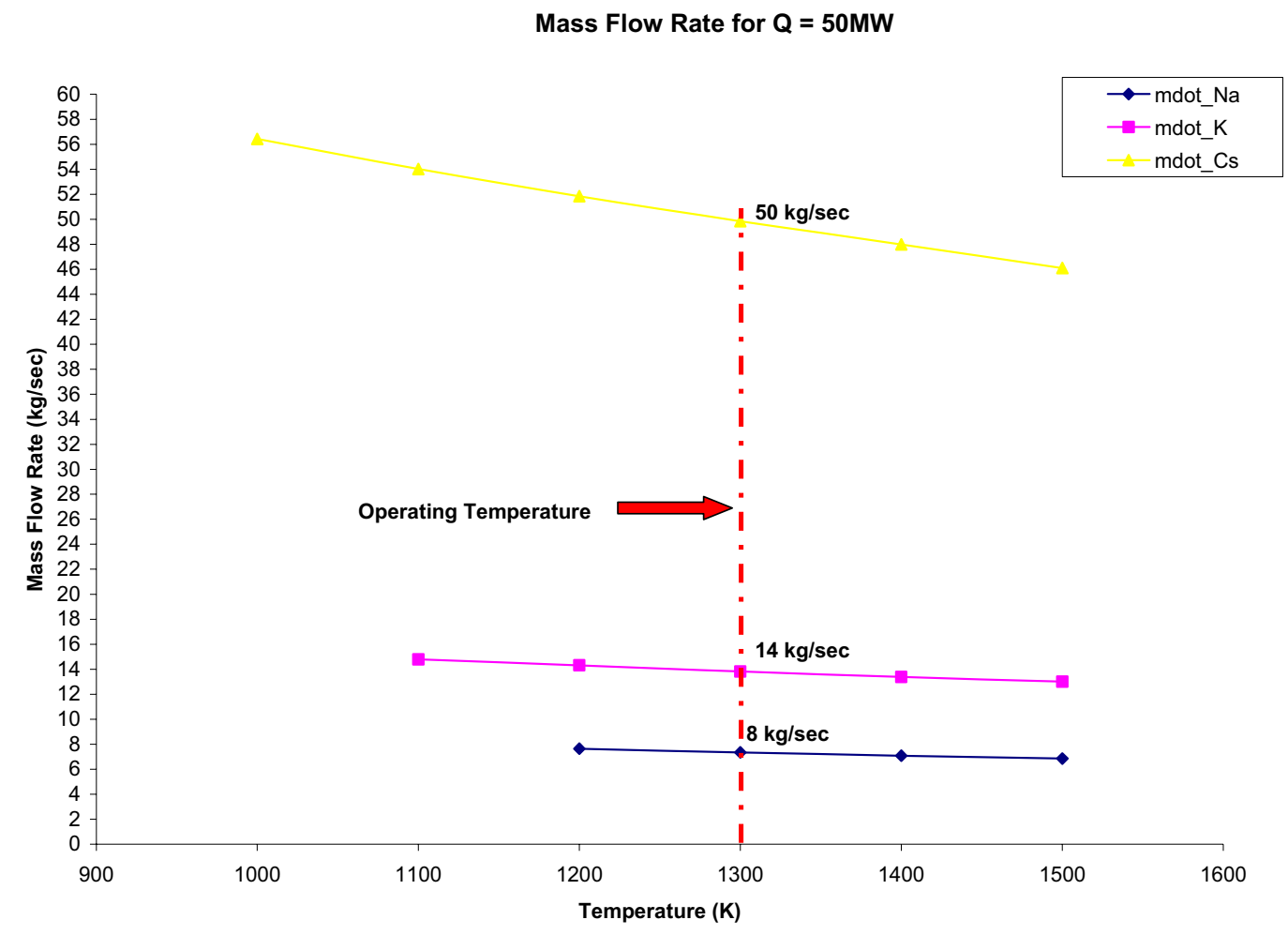

Figure 8. Mass Flow Rate of different alkali metals for heat input of $50 \mathrm{MW}$

For 50MW the lowest amount of mass flow rate was seen in $\mathrm{Na}$, as compared to other alkali metals. Further, the diameter of the pipe is calculated such that the respective mass flow is attained at the sonic velocity limitation, shown in Table 2. 
Table 2. Diameter of the thermosyphon (pipe) for various alkali metals

\begin{tabular}{|c|c|c|c|}
\hline $\mathbf{Q}(\mathbf{M W})$ & Diameter_Na $(\mathbf{m})$ & Diameter_K $(\mathbf{m})$ & Diameter_Cs $(\mathbf{m})$ \\
\hline 50 & 0.1271 & 0.0989 & 0.1074 \\
\hline
\end{tabular}

If we do have the alkali metal vapor at sonic velocity, we will have a shock wave propagating inside the thermosyphon. In order to avoid the shock wave we have to operate at velocity lower than sonic velocity, though by doing so we can reduce the heat transport capability of the thermosyphon if we do not maintain the constant mass flow rate. Following Table 3 show the respective diameter that we would need in order to maintain the same mass flow rate.

Table 3. Variation in Diameter(D) of the thermosyphon with the variation in Sonic Velocity (Vs) for various alkali coolants for $50 \mathrm{MW}$.

\begin{tabular}{|c|c|c|c|c|c|c|}
\hline Alkali Coolants & Vs (m/sec) & Dia $(\mathbf{m})$ & $\mathbf{V s / 2}(\mathbf{m} / \mathbf{s e c})$ & Dia $(\mathbf{m})$ & $\mathbf{V s} / \mathbf{4}(\mathbf{m} / \mathbf{s e c})$ & Dia $(\mathbf{m})$ \\
\hline $\mathbf{N a}$ & 744.694 & 0.1797 & 372.347 & 0.1797 & 186.1735 & 0.2542 \\
\hline $\mathbf{K}$ & 589.1 & 0.0989 & 294.55 & 0.14 & 147.275 & 0.198 \\
\hline $\mathbf{C s}$ & 310.9 & 0.1074 & 155.45 & 0.1518 & 77.725 & 0.2146 \\
\hline
\end{tabular}

\subsection{Comparison of Alkali Metals Thermosyphon with Convective Loop}

In this section the heat transport capability of a convective loop is compared to a thermosyphon on the basis of latent heat for the alkali metals. Single-phased forced convective heat transfer via 'pumping a fluid', a thermosyphon (also called a wickless heat pipe) transfers latent heat through the vaporization / condensing process. The condensate is further returned to the hot end by gravity, i.e. without any requirement of pumps or compressors. Since the latent heat of evaporation is large, a considerable amount of heat can be transported with a minimal temperature difference from end to end.

It is easy to demonstrate that a alkali metal filled thermosyphon can transport comparable amounts of thermal energy as a single-phase convective sodium loop, within the same diameter pipe. Alkali metal thermosyphon and alkali metal forced convective loops can both deliver comparable rates of heat transfer through a given size pipe. This can be easily demonstrated by considering the ideal rate of convective heat transport through a pipe without losses; modeled in terms of enthalpy by:

$$
Q^{\prime \prime}=\Delta \mathrm{H} \rho \mathrm{V}=\Delta \mathrm{H}\left(m^{\prime} / \mathrm{A}\right)
$$


where $Q^{\prime \prime}$ is the rate of thermal energy transport per unit flow area $\left(\mathrm{kJ} / \mathrm{m}^{2} \mathrm{~s}\right), \Delta \mathrm{H}$ is the change of the specific enthalpy of the transport fluid $(\mathrm{kJ} / \mathrm{kg}), \mathrm{V}$ is the average flow velocity $(\mathrm{m} / \mathrm{s}), m^{\prime}$ is the mass flow rate $(\mathrm{kg} / \mathrm{s}), \rho$ is density $\left(\mathrm{kg} / \mathrm{m}^{3}\right)$, and $\mathrm{A}$ is the cross-sectional flow area $\left(\mathrm{m}^{2}\right)$.

Two-phase heat transfer by a thermosyphon has the advantage of high enthalpy transport that includes the sensible heat of the liquid, the latent heat of vaporization, and possible vapor superheat. In contrast, singlephase forced convection transports only the sensible heat of the fluid. Additionally, vapor-phase velocities within a thermosyphon can be much greater than single-phase liquid velocities within a forced convective loop.

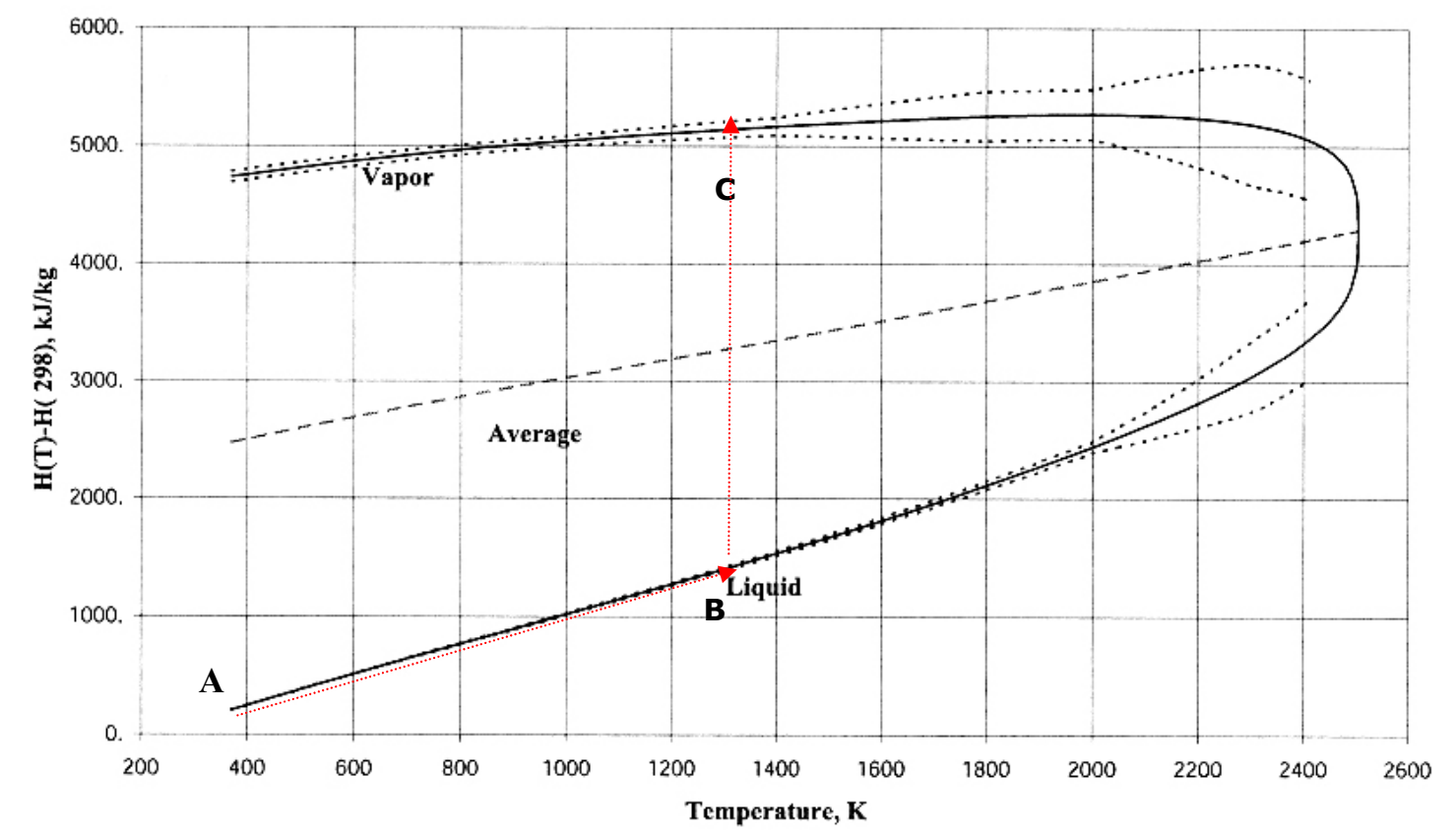

Figure 9. Enthalpy for saturated sodium: liquid and vapor [Gunnerson, F., et al., 2007]

Figure 9 exemplifies the enthalpy enhancement in heat transfer afforded by a two-phase thermosyphon verses a single-phase convective loop with sodium as the working fluid. The specific enthalpy $(\Delta \mathrm{H})$ of saturated liquid and vapor, relative to the solid at $298.15 \mathrm{~K}$, are illustrated as a function of temperature. Assuming heat transfer from a high-temperature gas cooled reactor at $1300 \mathrm{~K}\left(1027^{\circ} \mathrm{C}\right)$ to an industrial facility; the maximum singlephase heat transfer is given by the enthalpy from points A to B in Figure 5, or approximately 1,200 kJ for each kilogram of sodium. Compare with two-phase heat transfer from points $\mathrm{A}$ to $\mathrm{B}$ to $\mathrm{C}$ where the enthalpy is approximately 4,933 kJ per kilogram with no vapor superheat; over $3 \frac{1}{2}$ times more heat per kilogram of sodium than the single-phase. The saturation pressure of sodium at $1300 \mathrm{~K}$ is only $0.326 \mathrm{MPa}$ thus pressure forces are minimized. Vapor flow through a pipe is limited by compressible 'choke flow' when the vapor reaches its sonic velocity. For sodium vapor the sonic velocity is approximately $750 \mathrm{~m} / \mathrm{sec}$ at $1300 \mathrm{~K}$ [Bystrov, P.I., et al., 1990]. The limiting heat transfer rate for an ideal sodium thermosyphon operating around $1300 \mathrm{~K}$ can therefore be estimated by equation (1): 


$$
Q^{\prime \prime}=\Delta \mathrm{H} \rho \mathrm{V}=(4,933) \mathrm{kJ} / \mathrm{kg}(0.8) \mathrm{kg} / \mathrm{m}^{3}(750) \mathrm{m} / \mathrm{s}=2960 \mathrm{MW} / \mathrm{m}^{2}
$$

Similarly, single-phase liquid sodium could transport the same rate of thermal energy with an average flow velocity of about $3.5 \mathrm{~m} / \mathrm{s}$, well within the capabilities of advanced liquid metal pumps. This simple analysis for sodium as the working fluid theoretically illustrates that a thermosyphon and a forced convective loop can both deliver comparable rates of heat transfer through a comparable diameter pipe. An inclined thermosyphon, however, has the luxury of controllable heat transfer without the need for high temperature pumping and can deliver the heat at the same approximate temperature as the source.

Table 4, refers to the enthalpy gain that can be achieved by two-phase instead of single -phase and also the single-phase velocity which would be needed to transport the same rate of thermal energy as in two-phase, which is well within the capabilities of advanced liquid metal pumps.

Table 4. Enthalpy Gain for two-phase compared to single-phase

\begin{tabular}{|c|c|c|c|}
\hline Alkali Metal & Vs (m/sec) & Enthalpy Gain & $\mathbf{v}$ (single phase,m/sec) \\
\hline $\mathrm{Na}$ & 750 & 3.28185241 & 2.761403714 \\
\hline $\mathrm{K}$ & 589 & 2.454536419 & 8.100499592 \\
\hline $\mathrm{Cs}$ & 310 & 2.049760094 & 10.55893227 \\
\hline $\mathrm{Li}$ & 1456 & 4.973814384 & 0.074266324 \\
\hline
\end{tabular}

Ideally, a $15 \mathrm{~cm}$ diameter pipe could transport $\sim 50 \mathrm{MW}$ of power at $1300 \mathrm{~K}$ to a hydrogen production facility some distance away by serving either as a sodium thermosyphon or as part of forced-convective loop. A larger diameter thermosyphon could reduce the vapor velocity below limiting critical choke velocity. Therefore, the two-phase heat delivered by a sodium thermosyphon is comparable to that delivered by a single-phase forced convection loop. 


\subsection{Dimensional Analysis of a Thermosyphon}

Thermo-physical properties that are important to improve the heat transfer of a given thermosyphon are:

\section{Physical Quantity}

1 Length of the heat pipe

$\mathrm{V}_{\mathrm{s}} \quad$ Sonic velocity

$\mathrm{C}_{\mathrm{p}} \quad$ Specific Heat

$\mathrm{h}_{\mathrm{fg}} \quad$ Latent heat of vaporization

$\sigma \quad$ Surface tension

$\rho_{1} \quad$ Liquid density

$\rho_{\mathrm{v}} \quad$ Vapor density

$\mu \quad$ Liquid viscosity

D Diameter of the heat pipe

K Thermal conductivity of the liquid

m Mass flow rate

P Power

\section{Fundamental Dimensions}

$\mathrm{L}$

$\mathrm{L} \mathrm{T}^{-1}$

$\mathrm{L}^{2} \mathrm{~T}^{-2} \mathrm{Q}^{-1}$

$\mathrm{L}^{2} \mathrm{~T}^{-2}$

$\mathrm{M} \mathrm{T}^{-2}$

$\mathrm{M} \mathrm{L}^{-3}$

$\mathrm{M} \mathrm{L}^{-3}$

$\mathrm{M} \mathrm{L}^{-1} \mathrm{~T}^{-1}$

$\mathrm{L}$

$\mathrm{ML} \mathrm{T}^{-3} \mathrm{Q}^{-1}$

$\mathrm{M} \mathrm{T}^{-1}$

$\mathrm{M} \mathrm{L}^{2} \mathrm{~T}^{-3}$

The dimensions M, L, T, and Q correspond to mass, length, time and temperature; respectively. 
Repeating Variables: $\rho_{1}, D, \mu, C_{p}$

Number of physical quantity (n): 12

Fundamental Dimensions (k): M, L, T and Q i.e. 4

Therefore, number of Pi terms: $12-4=8$

$\Pi_{0}=\left(\rho_{1}\right)^{\mathrm{a}}(\mathrm{D})^{\mathrm{b}}(\mu)^{\mathrm{c}}\left(\mathrm{C}_{\mathrm{P}}\right)^{\mathrm{d}}(\mathrm{L})^{1}$

$M^{0} L^{0} T^{0} Q^{0}=\left(M L^{-3}\right)^{a}(L)^{b}\left(M L^{-1} T^{-1}\right)^{c}\left(L^{2} T^{-2} Q^{-1}\right)^{d}(1)^{1}$

Comparing the coefficients we get,

For $\mathrm{M}: 0=\mathrm{a}+\mathrm{c}$

For $\mathrm{L}: 0=-3 \mathrm{a}+\mathrm{b}-\mathrm{c}+2 \mathrm{~d}+1$

For $\mathrm{T}: 0=-\mathrm{c}-2 \mathrm{~d}$

For $\mathrm{Q}: 0=-\mathrm{d}$

Thus we get, $a=0 ; b=-1 ; c=0 ; d=0$

$\Pi_{0}=\frac{1}{\mathrm{D}}$ (First Pi term)

First pi term, is just the geometric ratio or an aspect ratio of the given heat pipe.

$\Pi_{1}=\left(\rho_{1}\right)^{\mathrm{a}}(\mathrm{D})^{\mathrm{b}}(\mu)^{\mathrm{c}}\left(\mathrm{C}_{\mathrm{P}}\right)^{\mathrm{d}}\left(\mathrm{V}_{\mathrm{s}}\right)^{1}$

$M^{0} L^{0} T^{0} Q^{0}=\left(M L^{-3}\right)^{a}(L)^{b}\left(M^{-1} T^{-1}\right)^{c}\left(L^{2} T^{-2} Q^{-1}\right)^{d}\left(L^{-1}\right)$ 
After balancing the coefficients we get,

$\mathrm{a}=1 ; \mathrm{b}=1 ; \mathrm{c}=-1 ; \mathrm{d}=0$

$\Pi_{1}=\frac{\rho_{1} V_{S} D}{\mu}($ Second Pi term)

Second pi term is the Reynolds number which is the ratio of inertial forces $\left(\rho_{1} V_{S}\right)$ to viscous forces $\left(\frac{D}{\mu}\right)$ and it quantifies the relative importance of these two types of forces for given flow conditions and is also used to identify different flow regimes, such as

laminar or turbulent flow.

$\Pi_{2}=\left(\rho_{1}\right)^{\mathrm{a}}(\mathrm{D})^{\mathrm{b}}(\mu)^{\mathrm{c}}\left(\mathrm{C}_{\mathrm{P}}\right)^{\mathrm{d}}\left(\mathrm{h}_{\mathrm{fg}}\right)^{1}$

$\mathrm{M}^{0} \mathrm{~L}^{0} \mathrm{~T}^{0} \mathrm{Q}^{0}=\left(\mathrm{M} \mathrm{L}^{-3}\right)^{\mathrm{a}}(\mathrm{L})^{\mathrm{b}}\left(\mathrm{M} \mathrm{L}^{-1} \mathrm{~T}^{-1}\right)^{\mathrm{c}}\left(\mathrm{L}^{2} \mathrm{~T}^{-2} \mathrm{Q}^{-1}\right)^{\mathrm{d}}\left(\mathrm{L}^{2} \mathrm{~T}^{-2}\right)^{1}$

After balancing the coefficients we get,

$a=2 ; b=2 ; c=-2 ; d=0$

$\Pi_{2}=\frac{\rho_{1}^{2} \mathrm{D}^{2} \mathrm{~h}_{\mathrm{fg}}}{\mu^{2}}$

$\Pi_{2}=\left(\frac{\rho_{1} h_{f g} \sigma}{\mu}\right)\left(\frac{\rho_{1} D^{2}}{\mu \sigma}\right)$

$\Pi_{2}=\underbrace{\left(\frac{\rho_{1} \mathrm{~h}_{\mathrm{fg}} \sigma}{\mu}\right)}_{\mathrm{N}} \underbrace{\left(\frac{\rho_{1} \mathrm{~V}_{\mathrm{S}}^{2} \mathrm{D}}{\sigma}\right)}_{\text {We }}\left(\frac{\mathrm{D}}{\mu \mathrm{V}_{\mathrm{S}}^{2}}\right)$

$\Pi_{2}=(\mathrm{N})(\mathrm{We})\left(\frac{\mathrm{D}}{\mu \mathrm{V}_{\mathrm{S}}^{2}}\right)$ (Third Pi term) 
Where, $\mathrm{N}$ and We corresponds to liquid transport factor and Weber number. The liquid transport factor is inferred from theoretical consideration of capillary pumping limit with negligible vapor pressure drop and in the absence of any gravitational forces. When the heat pipe is operated in inclined positions in the gravitational field, the gravity term must be added or subtracted depending on the orientation of the evaporator with respect to the condenser. The Weber number is the ratio of inertial force to surface tension force, this number is useful in analyzing thin film flows and the formation of droplets and bubbles. For Weber numbers greater than unity, the possibility of the entrainment exists, but in that case ' $D$ ' would be replaced by ' $\mathrm{L}_{1}$ ', which is the characteristic dimension associated with the wick surface.

$$
\Pi_{3}=\left(\rho_{1}\right)^{\mathrm{a}}(\mathrm{D})^{\mathrm{b}}(\mu)^{\mathrm{c}}\left(\mathrm{C}_{\mathrm{P}}\right)^{\mathrm{d}}(\sigma)^{1}
$$

$M^{0} L^{0} T^{0} Q^{0}=\left(M L^{-3}\right)^{a}(L)^{b}\left(M L^{-1} T^{-1}\right)^{c}\left(L^{2} T^{-2} Q^{-1}\right)^{d}\left(M T^{-2}\right)^{1}$

After balancing the coefficients we get,

$$
\begin{aligned}
& \mathrm{a}=1 ; \mathrm{b}=1 ; \mathrm{c}=-2 ; \mathrm{d}=0 \\
& \Pi_{3}=\frac{\rho_{1} \mathrm{D} \sigma}{\mu^{2}} \\
& \Pi_{3}=\underbrace{\left(\frac{\rho_{1} \sigma}{\mu \rho_{\mathrm{v}} \mathrm{V}_{\mathrm{S}}}\right)}_{\mathrm{F}_{\mathrm{N}}}\left(\frac{\mathrm{D} \rho_{\mathrm{V}} \mathrm{V}_{\mathrm{S}}}{\mu}\right) \\
& \Pi_{3}=\underbrace{\left(\frac{\rho_{l} \sigma}{\mu \rho_{v} V_{S}}\right)}_{F_{\mathrm{N}}}(\mathrm{Re})
\end{aligned}
$$

where $F_{N}$ refers to the heat pipe fluid number and is independent of any geometric parameters. This parameter indicates the temperature at which the transition from the sonic limit to the capillary pumping limit will occur. 
From equation 15, we have

$$
\Pi_{3}=\underbrace{\frac{\rho_{l} D \sigma}{\mu}}_{M} \text { (Fourth Pi term) }
$$

The fourth Pi term is the non dimensional term, known as Merit number. If vapor pressure loss and gravitational head can be neglected then the properties of the working fluid which determine the maximum heat transport can be obtained from this Merit number.

$\Pi_{4}=\left(\rho_{1}\right)^{\mathrm{a}}(\mathrm{D})^{\mathrm{b}}(\mu)^{\mathrm{c}}\left(\mathrm{C}_{\mathrm{P}}\right)^{\mathrm{d}}(\mathrm{K})^{1}$

$\mathrm{M}^{0} \mathrm{~L}^{0} \mathrm{~T}^{0} \mathrm{Q}^{0}=\left(\mathrm{M} \mathrm{L}^{-3}\right)^{\mathrm{a}}(\mathrm{L})^{\mathrm{b}}\left(\mathrm{M} \mathrm{L}^{-1} \mathrm{~T}^{-1}\right)^{\mathrm{c}}\left(\mathrm{L}^{2} \mathrm{~T}^{-2} \mathrm{Q}^{-1}\right)^{\mathrm{d}}\left(\mathrm{M} \mathrm{L} \mathrm{T}^{-3} \mathrm{Q}^{-1}\right)^{1}$

After balancing the coefficients we get,

$\mathrm{a}=0 ; \mathrm{b}=0 ; \mathrm{c}=-1 ; \mathrm{d}=-1$

$\Pi_{4}=\frac{\rho_{1}^{0} \mathrm{D}^{0} \mathrm{~K}}{\mathrm{C}_{\mathrm{P}} \mu}$

$\Pi_{4}=\frac{\mathrm{K}}{\mathrm{C}_{\mathrm{P}} \mu}=\frac{1}{\operatorname{Pr}}$ (Fifth Pi Term)

The fifth pi term is the inverse of Prandtl number which approximates the ratio of momentum diffusivity (viscosity) and thermal diffusivity.

$\Pi_{5}=\left(\rho_{1}\right)^{\mathrm{a}}(\mathrm{D})^{\mathrm{b}}(\mu)^{\mathrm{c}}\left(\mathrm{C}_{\mathrm{P}}\right)^{\mathrm{d}}(\dot{\mathrm{m}})^{1}$

$\mathrm{M}^{0} \mathrm{~L}^{0} \mathrm{~T}^{0} \mathrm{Q}^{0}=\left(\mathrm{M} \mathrm{L}^{-3}\right)^{\mathrm{a}}(\mathrm{L})^{\mathrm{b}}\left(\mathrm{M} \mathrm{L}^{-1} \mathrm{~T}^{-1}\right)^{\mathrm{c}}\left(\mathrm{L}^{2} \mathrm{~T}^{-2} \mathrm{Q}^{-1}\right)^{\mathrm{d}}\left(\mathrm{M} \mathrm{T}^{-1}\right)^{1}$ 
After balancing the coefficients we get,

$a=0 ; b=-1 ; c=-1 ; d=0$

$\Pi_{5}=\frac{\mathrm{m}}{\mu \mathrm{D}}$

$\Pi_{5}=\underbrace{\left(\frac{\rho_{1} \mathrm{~V}_{\mathrm{S}} \mathrm{D}}{\mu}\right)}_{\text {Re }} \underbrace{\left(\frac{\mathrm{A}}{\mathrm{D}^{2}}\right)}_{\text {Dimensionless Geometric Parameter }}$

$\Pi_{5}=\operatorname{Re}\left(\frac{\mathrm{A}}{\mathrm{D}^{2}}\right)$ (Sixth Pi term)

The sixth Pi term has both dependence of fluid flow properties (Re) and geometric parameters. Reynolds number which is the ratio of inertial forces $\left(\rho_{1} V_{S}\right)$ to viscous forces $\left(\frac{D}{\mu}\right)$ and also quantifies the relative importance of these two types of forces for given flow conditions and is used to identify different flow regimes, such as laminar or turbulent flow.

$\Pi_{6}=\left(\rho_{1}\right)^{\mathrm{a}}(\mathrm{D})^{\mathrm{b}}(\mu)^{\mathrm{c}}\left(\mathrm{C}_{\mathrm{P}}\right)^{\mathrm{d}}\left(\rho_{\mathrm{V}}\right)^{1}$

$\mathrm{M}^{0} \mathrm{~L}^{0} \mathrm{~T}^{0} \mathrm{Q}^{0}=\left(\mathrm{M} \mathrm{L}^{-3}\right)^{\mathrm{a}}(\mathrm{L})^{\mathrm{b}}\left(\mathrm{M} \mathrm{L}^{-1} \mathrm{~T}^{-1}\right)^{\mathrm{c}}\left(\mathrm{L}^{2} \mathrm{~T}^{-2} \mathrm{Q}^{-1}\right)^{\mathrm{d}}\left(\mathrm{M} \mathrm{L} \mathrm{L}^{-3}\right)^{1}$

After balancing the coefficients we get,

$a=-1 ; b=0 ; c=0 ; d=0$

$\Pi_{6}=\frac{\rho_{\mathrm{V}}}{\rho_{1}}$ 
Equation 30 is just the density ratio of the vapor to the liquid phase.

$$
\Pi_{6}=\underbrace{\left(\frac{\rho_{1} \sigma}{\mu \rho_{\mathrm{v}} \mathrm{V}_{\mathrm{S}}}\right)}_{\mathrm{F}_{\mathrm{N}}} \underbrace{\left(\frac{\mu \mathrm{V}_{\mathrm{S}}}{\sigma}\right)}_{\mathrm{Ca}}
$$

$\Pi_{6}=\left(\mathrm{F}_{\mathrm{N}} \mathrm{Ca}\right)($ Seventh Pi term)

The seventh $\mathrm{Pi}$ term is the product of two dimensionless numbers, i.e. $\mathrm{F}_{\mathrm{N}}$ and Ca respectively. $\mathrm{F}_{\mathrm{N}}$ is the heat pipe fluid number which is independent of any geometric parameters. This parameter indicates the temperature at which the transition from the sonic limit to the capillary pumping limit will occur. $\mathrm{Ca}$ is the capillary number which represents the relative effect of viscous forces versus surface tension acting across an interface between a liquid and vapor.

$$
\Pi_{7}=\left(\rho_{1}\right)^{\mathrm{a}}(\mathrm{D})^{\mathrm{b}}(\mu)^{\mathrm{c}}\left(\mathrm{C}_{\mathrm{P}}\right)^{\mathrm{d}}(\mathrm{P})^{1}
$$

$M^{0} L^{0} T^{0} Q^{0}=\left(M L^{-3}\right)^{a}(L)^{b}\left(M L^{-1} T^{-1}\right)^{c}\left(L^{2} T^{-2} Q^{-1}\right)^{d}\left(M ~ L^{2} T^{-3}\right)^{1}$

After balancing the coefficients we get,

$$
a=2 ; b=1 ; c=-3 ; d=0
$$

$$
\Pi_{7}=\frac{\rho_{1}^{2} \mathrm{D} \mathrm{P}}{\mu^{3}}
$$

$$
\Pi_{7}=\left(\frac{\rho_{1} \mathrm{~V}_{\mathrm{s}} \mathrm{D}}{\mu}\right)\left(\frac{\rho_{1} \mathrm{P}}{\mu^{2} \mathrm{~V}_{\mathrm{s}}}\right)
$$

$$
\Pi_{7}=(\operatorname{Re})\left(\frac{\rho_{1} \mathrm{P}}{\mu} \frac{1}{\mu \mathrm{V}_{\mathrm{s}}}\right)
$$


$\Pi_{7}=(\operatorname{Re})\left(\frac{\mathrm{ML}^{-3} \mathrm{~L}^{2} \mathrm{~T}^{-1}}{\mathrm{ML}^{-1} \mathrm{~T}^{-1}} \frac{\mathrm{MT}^{-2}}{\mathrm{ML}^{-1} \mathrm{~T}^{-1} \mathrm{~L} \mathrm{~T}^{-1}}\right)$

$\Pi_{7}=(\operatorname{Re})\left(\frac{\sigma}{\mu \mathrm{V}_{\mathrm{s}}}\right)$

$\Pi_{7}=(\mathrm{Re})(\mathrm{Ca})$ (Eighth Pi term)

Reynolds number which is the ratio of inertial forces $\left(\rho_{1} V_{S}\right)$ to viscous forces $\left(\frac{D}{\mu}\right)$ and also quantifies the relative importance of these two types of forces for given flow conditions. $\mathrm{Ca}$ is the capillary number which represents the relative effect of viscous forces versus surface tension acting across an interface between a liquid and vapor. 


\section{Intermediate Heat Exchanger}

The Next Generation Nuclear Plant (NGNP) will most likely be producing electricity and process heat, with both being used for hydrogen production. For process heat, intermediate heat exchanger (IHX) is required to transfer heat from the NGNP to the hydrogen plant in the most efficient way possible [Davis, et. al., 2005]. The production of power at higher efficiency using Brayton Cycle, and hydrogen production requires both heat at higher temperatures, up to $1000^{\circ} \mathrm{C}$ and high effectiveness compact heat exchanger to transfer heat to either the power or process cycle. The purpose for selecting a compact heat exchanger is to maximize the heat transfer surface area per volume of heat exchanger, this has the benefit of reducing heat exchanger size. The IHX design requirements are governed by the allowable temperature drop between the outlet of the NGNP $\left(900^{\circ} \mathrm{C}\right.$, based on the current capabilities of NGNP), and the temperatures in the hydrogen production plant. Two alternatives for hydrogen production are: High Temperature Electrolysis (HTE) and thermochemical sulfur-iodine (SI) cycle. HTE operates at temperatures in excess of $750^{\circ} \mathrm{C}$, with temperatures in the vicinity of $850^{\circ} \mathrm{C}$ preferred for achieving high efficiency. The maximum temperature in the SI process is $\sim 850^{\circ} \mathrm{C}$, with another endothermic reaction step operating at $\sim 450^{\circ} \mathrm{C}$. The maximum temperature drop for the primary coolant in $\mathrm{IHX}$ is $400^{\circ} \mathrm{C}$ $\left(900 \rightarrow 500^{\circ} \mathrm{C}\right)$, which is comparable to the temperature rise across the core of the NGNP. The temperature rise of secondary coolant in the IHX, is constrained by these temperatures of the primary coolant, and the process requirements of the hydrogen plant, mentioned above. Irrespective of the NGNP reactor type (i.e. prismatic core or pebble bed) and the resultant coolant the key to high efficiency is a high effectiveness heat exchange. Efficient design of the IHX is critical for effective utilization of the energy generated in the NGNP, so a compact heat exchanger is chosen, as it exhibits high area density i.e. high heat transfer surface to volume ratio.

The design of the intermediate heat exchanger requires the reconciliation of a large number of considerations, mainly including:

1. Compact heat exchanger to improve safety and economics

2. Achieving the required thermal effectiveness ( boundary temperature limitation for efficient heat transfer to hydrogen plant) at minimal pressure drop

3. Choosing suitable materials for construction to address the high temperature and corrosion issues

4. Ensuring valid mechanical design and sustainability at high operating temperature

IHX designs being considered between the NGNP and the hydrogen plant are: Printed-Circuit heat exchanger (PCHE), and spiral heat exchanger (SHE). Both have benefits and drawbacks. The key significant characteristics are low heat losses because of its compactness, close temperature approach and less pumping power compared to the conventional heat exchangers. In order to achieve a high degree of compactness the tube 
diameters would have to be very small, this would introduce difficulties in manufacturing [Davis, et al., 2005]. It may also be necessary to consider an exchanger with very different passage sizes on the primary and secondary side, both the compact design discussed here offer such flexibility. The optimum passage geometries and sizes for liquid metals, or molten salt are very different from those for a gas such as helium, nitrogen or carbon dioxide.

\subsection{Printed Circuit Heat Exchanger (PCHE)}

PCHE's are robust heat exchangers which combine compactness, low pressure drop, high effectiveness and the ability to operate with a very large pressure differential between hot and cold sides and are manufactured by HEATRIC (United Kingdom). PCHEs are "compact" relative to conventional heat exchangers, but they are not necessarily "small". Single units of up to 100 tons have been manufactured, and clearly these are only "compact" in comparison to the 500 tons alternatives [Johnston, et al., 2007]. These heat exchangers are not sensitive to high pressures and high-pressure differentials since they consist of many plates into which the channels are chemically etched, followed by diffusion bonding to form a monolithic block [Dostal, et al., 2004]. These heat exchangers are especially well suited where compactness is very important. They are constructed by chemically etching small semicircular channels into plates as shown in Figure 10 (a). Plates are then stacked alternating between hot and cold side as shown in Figure 10 (b), then diffusion bonded together to form a monolithic heat exchanger core. Figure 10 (c) shows a photomicrograph of a cross section of three hot and three cold channels after bonding.

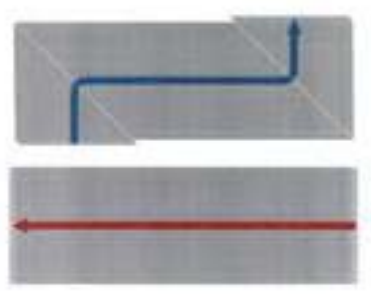

(a)

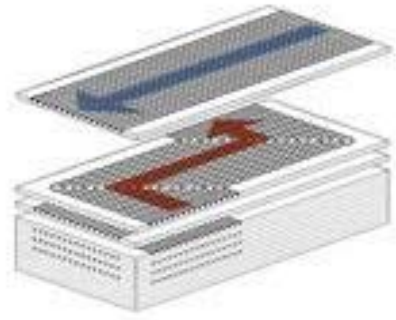

(b)

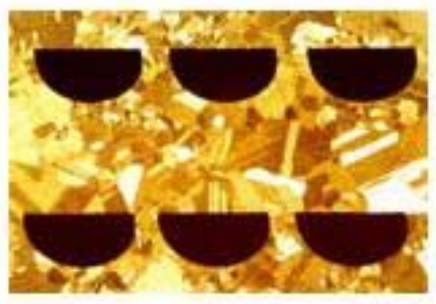

(c)

Figure 10. Heatric Printed Circuit Heat Exchangers. [from www.heatric.com]

The HEATRIC heat exchangers are available in stainless steel and high temperature alloys, i.e. both austenitic and ferritic steels and advanced alloys that are suitable for diffusion bonding. Carbon steels cannot be used for two reasons [Dostal, et al., 2004]. The first is difficulty in the diffusion bonding process. The second is the fact that HEATRIC heat exchangers are designed with zero corrosion allowance (because of their small 
channels), hence a carbon steel could introduce plugging problems. For most applications HEATRIC found the economic thermal performance optimum channel diameter to be $2 \mathrm{~mm}$. Nevertheless, much smaller diameters are possible. If larger flow area is required on one side (gas/liquid metal application) it is better to use two (or more) plates for one fluid and one plate for the other, which doubles (or more than doubles) the flow area. The only liquid metal used in HEATRIC heat exchangers so far was mercury, but conceptually there is no reason why other liquid metals could not be used. Having small channels for the PCHE design is an additional safety that this heat exchanger offers, because the probability of leak is very low and secondly if leak does occur it is very small and is spot welded to close the leak.

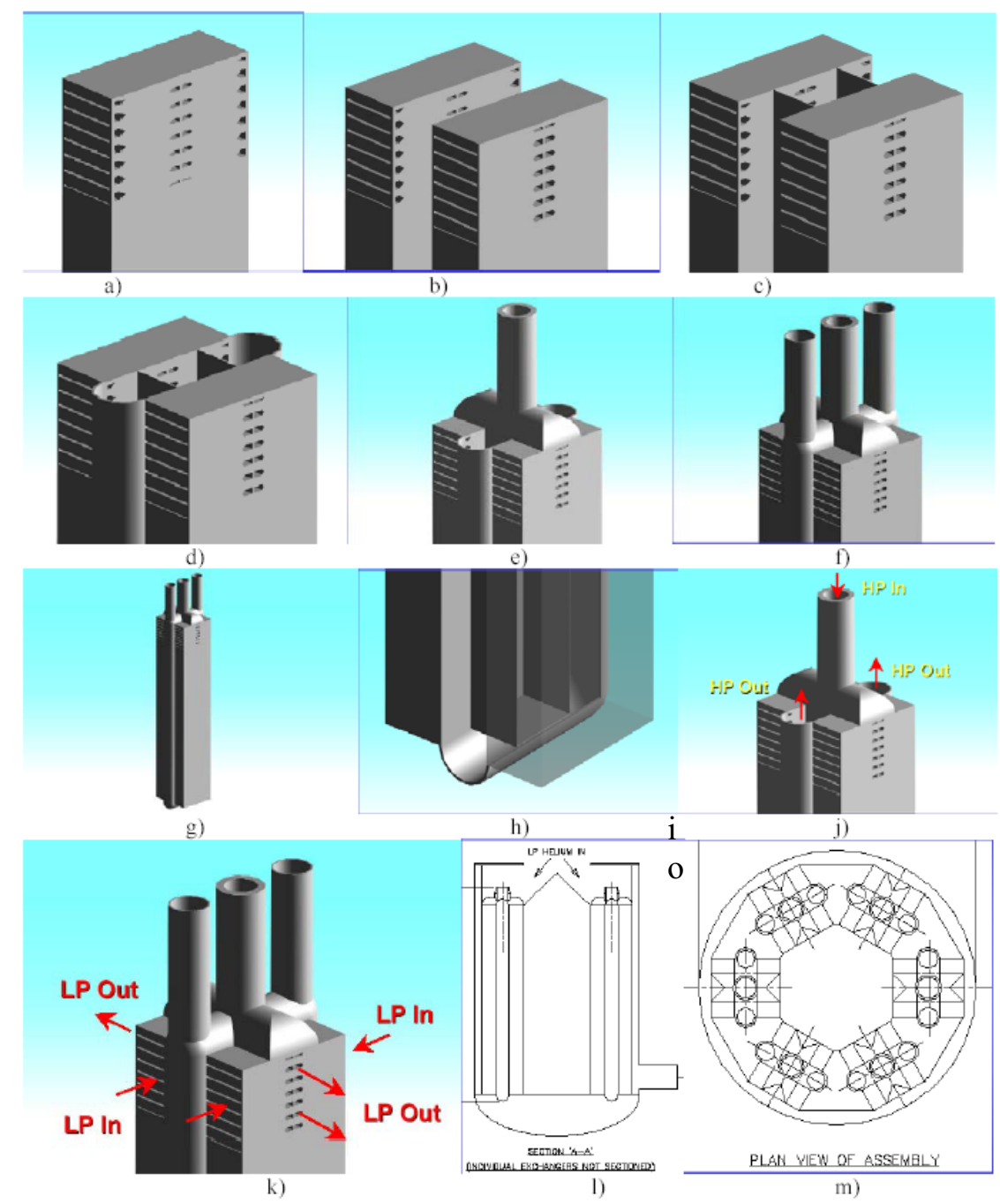

Figure 11. Assembling sequence of the new PCHE design [Dewson, S.J., et al., 2003]

Figure 10 shows the stacked plates for the PCHE heat exchanger. Figure 11 (a) of the figure shows the plates after going through the diffusion bonding process. The maximum height of this stack is currently $1500 \mathrm{~mm}$, but can be increased. Two diffusion bonded stack of the plates are shown in Figure 11 (b). In order to keep the hot 
end and cold end entrance separate sheets are used as can be seen in Figure 11 (c) and Figure 11 (d). Figure 11 (e) and Figure 11 (f) show the connection of the inlet and outlet piping for one of the fluids. The whole module is shown in Figure $11(\mathrm{~g})$. The bottom header in detail is shown in Figure $11(\mathrm{~h})$. Figure 11 (i) shows the flow path for the high pressure fluid, which is placed on the inside in order to minimize the stresses. Figure $11(\mathrm{k})$ explains the flow path of the low pressure fluid. The arrangement of the 6 modules inside the pressure vessel is shown in Figure 11 (1) and Figure 11 (m). This design was developed for the helium Brayton cycle [Dewson., et al., 2003]. A similar layout would be well suited for the intermediate heat exchanger setup in order to transfer the heat efficiently. Figure 12 below shows the current operating experience with HEATRIC heat exchangers.

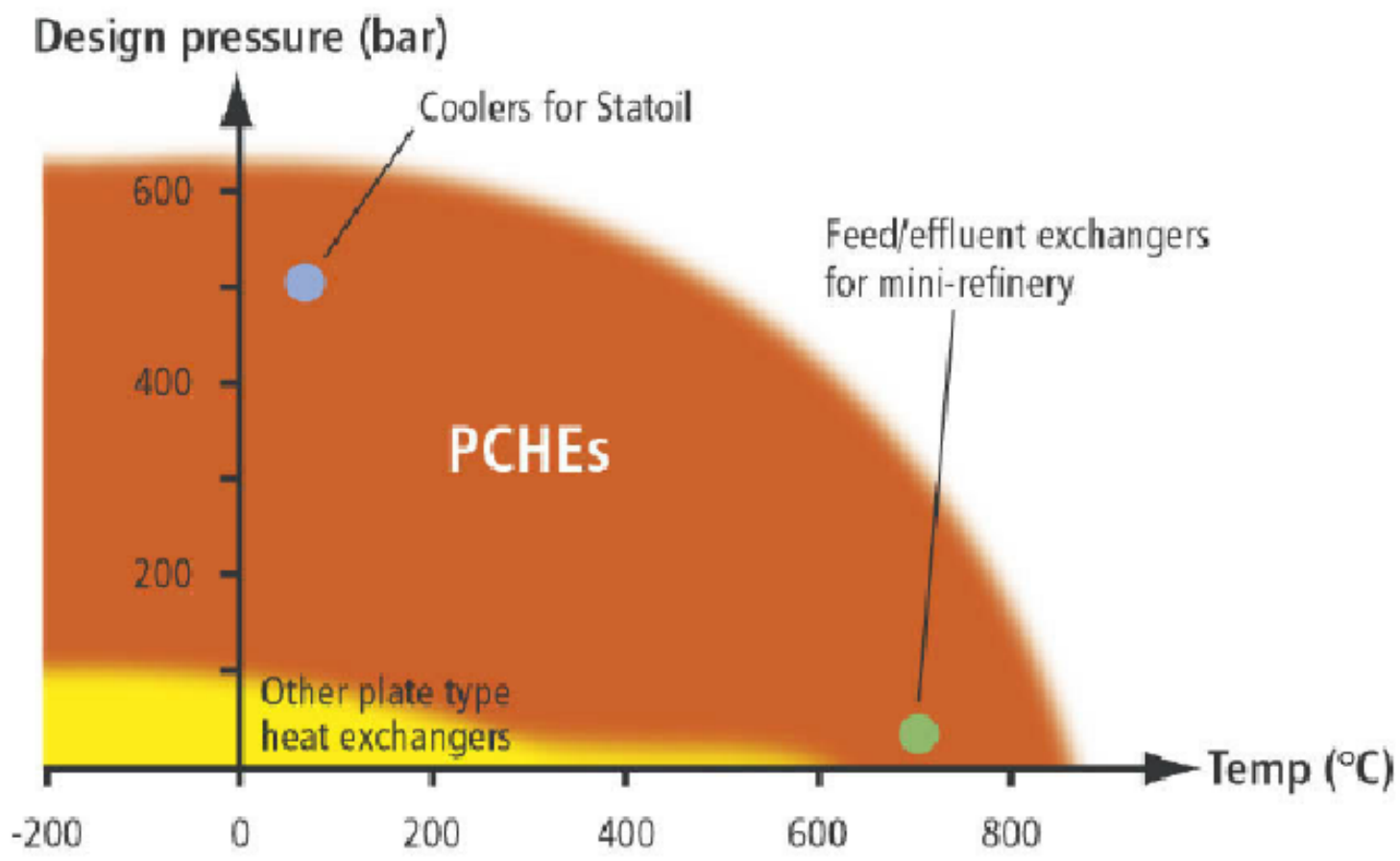

Figure 12. Current operating experience of HEATRIC PCHEs [Dewson, S.J. et al., 2003] 


\subsection{Spiral Heat Exchanger (SHE)}

Spiral heat exchanger (SHE) designs as shown in Figure 13, are less susceptible to fouling, and are more compact than conventional shell and tube designs resulting in reduced heat losses. Due to curvature of the tube, a centrifugal force is generated as the fluid flows through the curved tubes. The curved channels create a swirling or spiraling motion within the fluid. This spiraling motion helps keeps the solid present (if any) in fluid in suspension, and the heat transfer surfaces are kept clean through a scrubbing action. The flow is generally turbulent, even when flowing at velocities that would otherwise make the flow non-turbulent in straight tubes [Sabharwall, P., et al., 2007]. Secondary flow induced by the centrifugal force has significant ability to enhance the heat transfer rate. SHE have been extensively used in a wide variety of applications for example, air conditioning and refrigeration systems. Heat transfer characteristics of SHE can be enhanced through manipulation of channel dimension (i.e. by varying the diameter of the pipe) and surface modifications by adding roughness to the pipe.

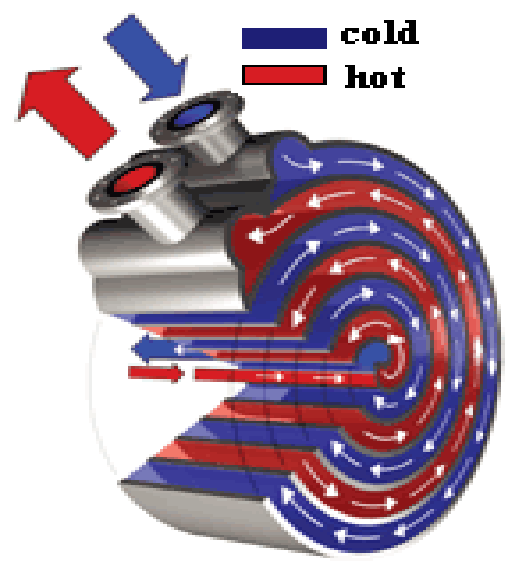

Figure 13. Schematic of a Spiral Heat Exchanger

The SHE could be efficient phase change exchanger. The specific volume change from convective evaporation and condensation is well accommodated by the spiral design. Liquid flows into the eye of the spiral, gains heat, and vapor exits from the spiral 'horn' for transport to the distant condenser at the industrial end user.

In this paper the case study is presented for the evaporative SHE design, where the transfer of thermal energy of the NGNP will be utilized for the boiling of sodium and further this heat will be used in the production of hydrogen. The approach to the development of the model involves writing energy balance equations for the two fluids over a differential element of the SHE. Figures 14 and 16 show the flow paths of the two fluids and clarifies the basis for modeling of the SHE. 


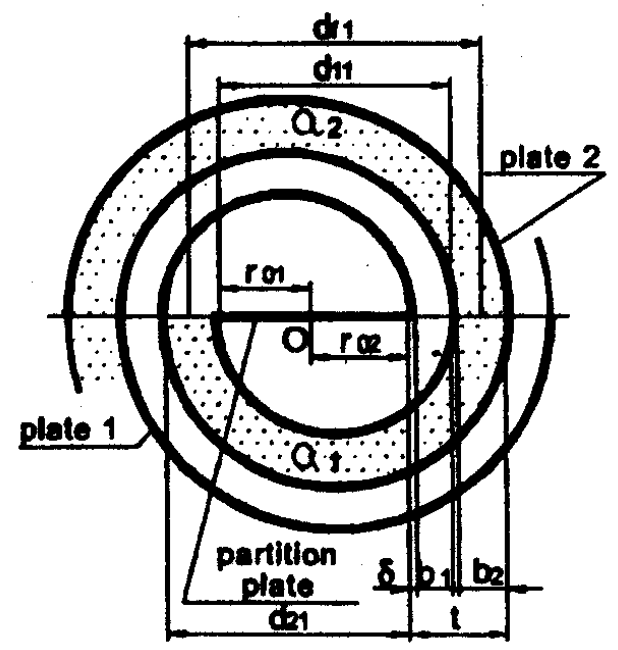

Figure 14. Flow Path for Cold and Hot Fluids

The energy balance equations for the hot and cold fluid are [Bes, T.H., and Roetzel, W., 1993]:

$$
\begin{aligned}
& -\mathrm{C}_{\mathrm{H}} \frac{\mathrm{dt}_{\mathrm{H}, \mathrm{r}-\frac{1}{2}}}{\mathrm{~d} \varphi}=\mathrm{q}_{\mathrm{i}, \mathrm{j}-1}+\mathrm{q}_{\mathrm{i}, \mathrm{j}+1} \\
& -\mathrm{C}_{\mathrm{C}} \frac{\mathrm{dt}_{\mathrm{C}, \mathrm{r}+\frac{1}{2}}}{\mathrm{~d} \varphi}=\mathrm{q}_{\mathrm{i}, \mathrm{j}+1}+\mathrm{q}_{\mathrm{i}+1, \mathrm{j}+2}
\end{aligned}
$$

Where, $\mathrm{C}_{\mathrm{H}}$ and $\mathrm{C}_{\mathrm{C}}$ are the heat capacity rates (products of mass flow rates and heat capacities), $\mathrm{q}$ are the heat fluxes, $\mathrm{t}$ are the dimensionless temperatures, and $\varphi$ the differential angle over which the energy balance is written. The subscripts $\mathrm{i}, \mathrm{j}$ and $\mathrm{r}$ refer to the spiral positions.

Some assumptions typically made for developing the mathematical models for the SHE are:

○ The fluid physical properties are uniform in each phase i.e. they are invariant for liquid sodium and also for sodium vapor, though the properties of liquid sodium are different than that of sodium vapor.

○ Radiative heat transfer is negligible

- Heat losses from the outer surface to the surroundings are negligible

○ Thermal resistance of the channel wall is negligible 


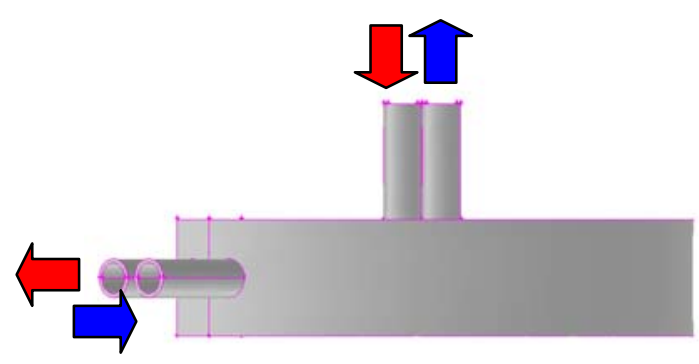

Figure 15. Modeled Geometry of the Spiral Heat Exchanger (SHE)

The inlet and outlet of the hot and cold fluid can be seen from the Figure 15, inlet of the hot fluid will be connected with the next generation nuclear plant and the outlet of the cold fluid (in vaporized state) will be connected to a thermosyphon or a heat pipe for further transport of heat to a hydrogen plant. The direction of the coolant motion in SHE is shown below. The hot fluid enters at the center, as can be seen from the red arrow and flows outward in a spiral path to the outlet on periphery. The cold fluid (Na) simultaneously enters the peripheral header, as can be seen from the blue arrow and flow countercurrent to the hot fluid toward the center.

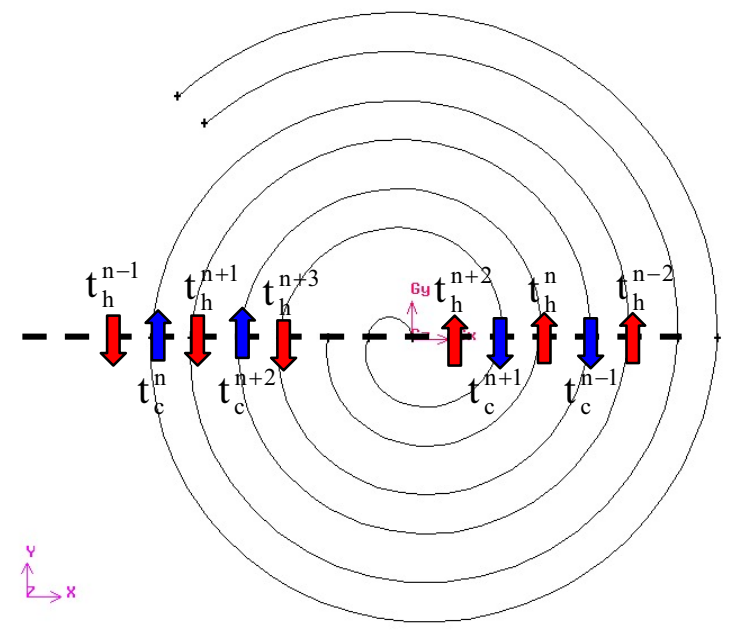

Figure 16. Detail Description of the Fluid Flow Motion and Heat Transfer Between Adjacent elements for the Spiral Heat Exchanger

The SHE model with 6 spirals was modeled in FLUENT and Nusselt number obtained from FLUENT was benchmarked against Dittus Boelter correlation. 


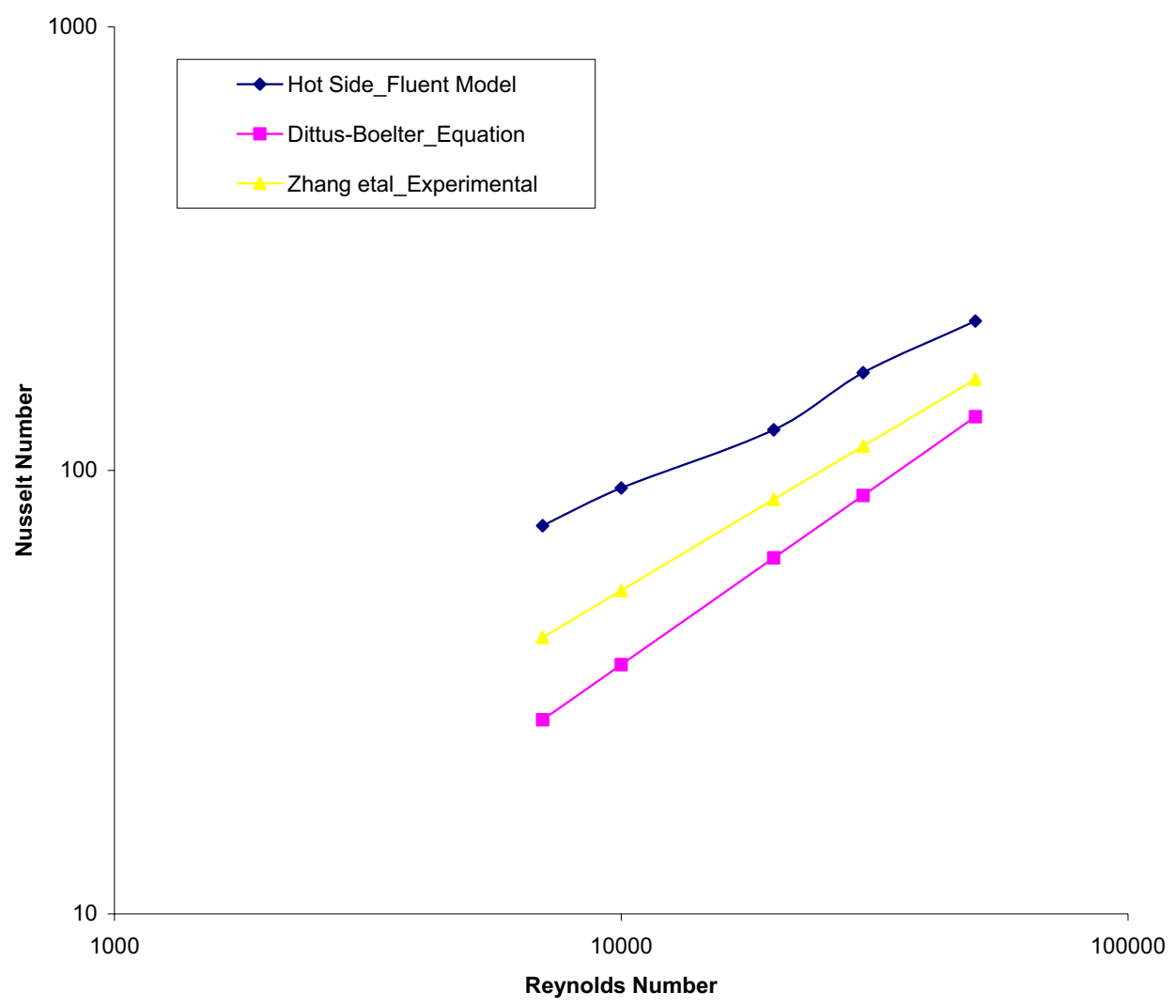

Figure 17. Benchmarking of the Hotter side of SHE with the Dittus Boelter Correlation

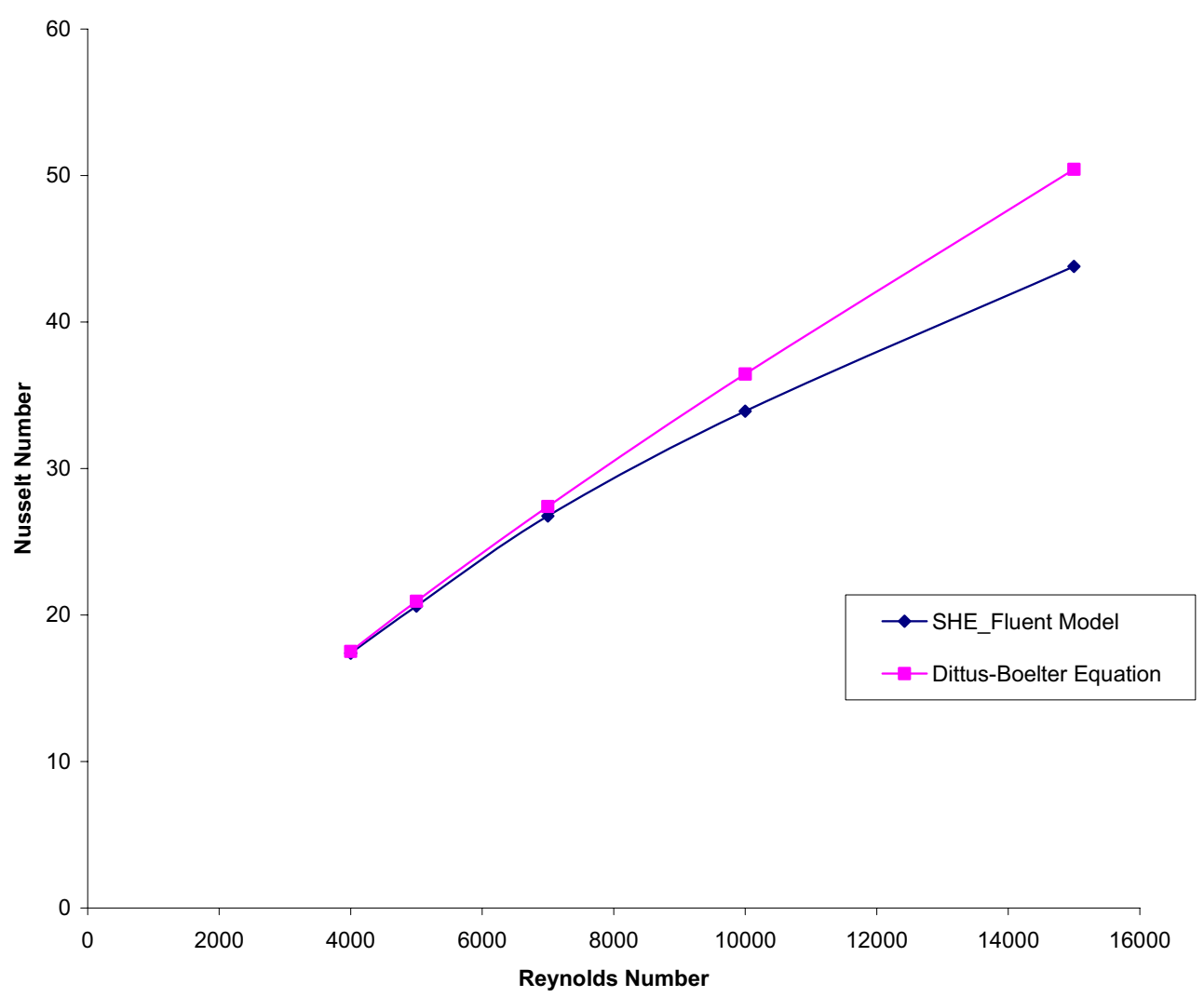

Figure 18. Benchmarking of the Cold side of SHE with the Dittus Boelter Correlation 
Figure 17, is on a log-log scale and as can be seen that the FLUENT model predicts the hot side behavior reasonably well when compared with the Dittus-Boelter correlation. In Figure 18, the Nusselt number calculated was in good agreement with the Dittus Boelter correlation. As can be seen from the above figures that the FLUENT model is in a better agreement with the Dittus Boelter correlation for the cold side when compared with the hot side, this may be because of the larger diameter of the hot side pipe. The diameter of the cold side pipe is 2.5 times smaller than the hot side. The other salient observation is that the Dittus-Boelter correlation is not able to predict behavior for higher Reynolds number (greater than 10000) for spiral heat exchanger and thus some experimental data is required in order to predict the behavior. 


\section{High Temperature Materials}

The candidate materials used in the construction of thermosyphon and in the construction of compact heat exchanger will need to be available in the appropriate product forms, be weldable and be suitable for use at temperature up to $1000^{\circ} \mathrm{C}$.

Table 5. Candidate material for construction of Thermosyphon [Dewson, S.J. et al., 2005]

\begin{tabular}{|l|c|c|c|l|}
\hline \multicolumn{1}{|c|}{ Alloys } & $\mathbf{T}^{\text {max }}\left({ }^{\circ} \mathbf{C}\right)$ & $\mathbf{S}^{898 \mathrm{C}}(\mathbf{M P a})$ & El (\%) & Nominal Compositions (wt\%) \\
\hline 617 & 982 & 12.4 & 30 & 52Ni-22Cr-13Co-9Mo-1.2Al \\
\hline 556 & 898 & 11 & 40 & $21 \mathrm{Ni}-30 \mathrm{Fe}-22 \mathrm{Cr}-18 \mathrm{Co}-3 \mathrm{Mo}-3 \mathrm{~W}-0.3 \mathrm{Al}$ \\
\hline $800 \mathrm{HT}$ & 898 & 6.3 & 30 & $33 \mathrm{Ni}-42 \mathrm{Fe}-21 \mathrm{Cr}$ \\
\hline $800 \mathrm{H}$ & 898 & 5.9 & 30 & $33 \mathrm{Ni}-42 \mathrm{Fe}-21 \mathrm{Cr}$ \\
\hline 330 & 898 & 3.3 & 30 & Fe-35Ni-19Cr-1.25 Si \\
\hline 230 & 898 & 10.3 & 40 & $57 \mathrm{Ni}-22 \mathrm{Cr}-14 \mathrm{~W}-2 \mathrm{Mo}-0.3 \mathrm{Al}-0.05 \mathrm{La}$ \\
\hline $\mathrm{HX}$ & 898 & 8.3 & 35 & $47 \mathrm{Ni}-22 \mathrm{Cr}-9 \mathrm{Mo}-18 \mathrm{Fe}$ \\
\hline $253 \mathrm{MA}$ & 898 & 4.9 & 40 & $\mathrm{Fe}-21 \mathrm{Cr}-11 \mathrm{Ni}-0.2 \mathrm{~N}$ \\
\hline
\end{tabular}

Among these alloys, alloy 617 , has the highest design temperature $\left(982^{\circ} \mathrm{C}\right)$ and therefore becomes worthy of further consideration, as a candidate material for construction of thermosyphon. However, design temperature alone is not the sole basis for material selection, consideration must also be given to the allowable design stress at temperature shown in Figure 19.

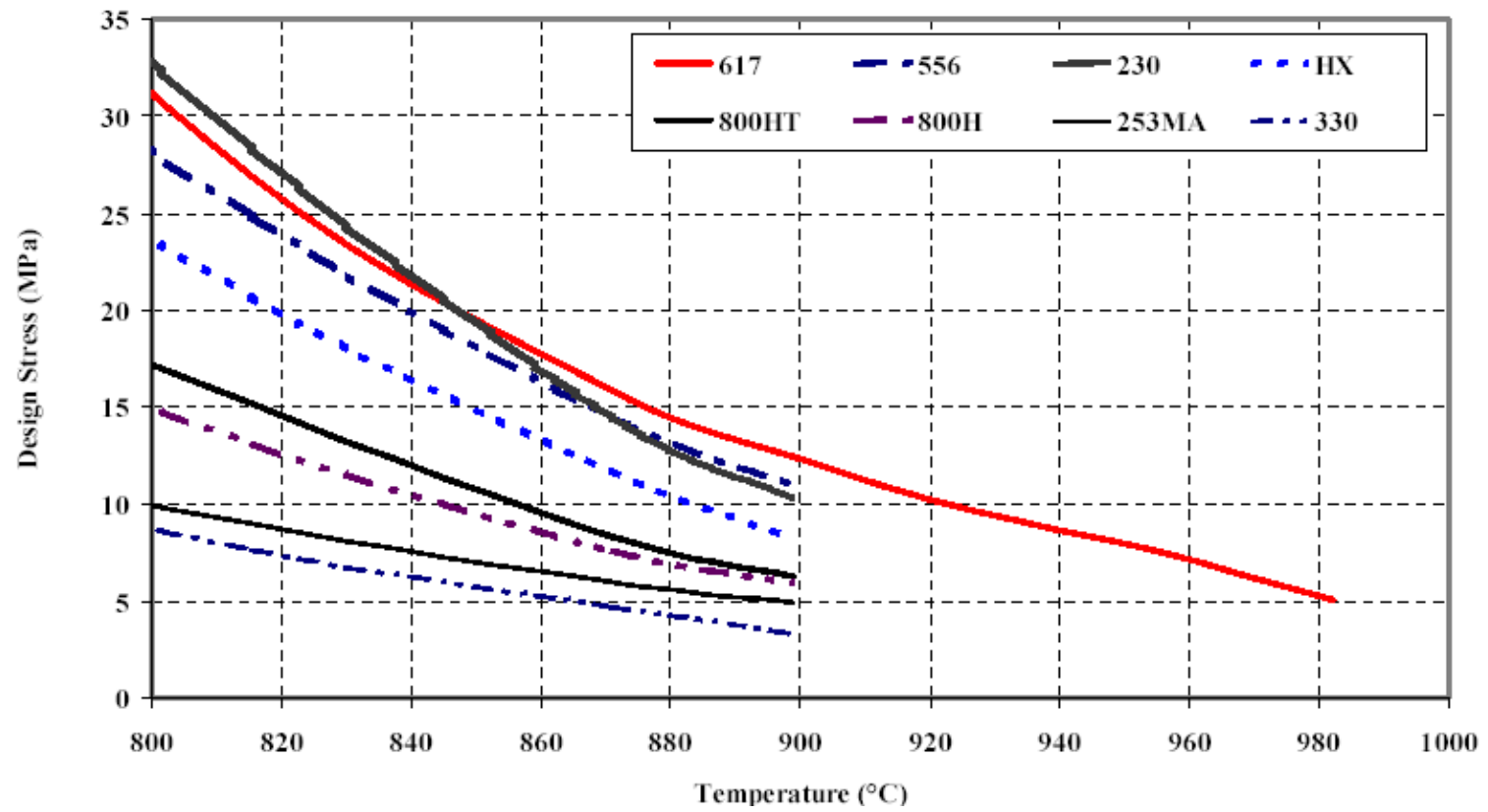

Figure 19. Comparison of ASME allowable stress for high temperature alloys [Li, X., et al., 2006] 


\section{Ductility and Creep Rupture Life}

From the above figure, at $898^{\circ} \mathrm{C}$ (the temperature for which the data is available) the design stress range from 12.4 $\mathrm{MPa}$ (alloy 617) to 3.3 MPa (alloy 330). Long term exposure (8000 hrs) to high temperatures, may cause alloys to alter their microstructure, from the ductility stand point the best four candidates are:

Table 6. Candidate material ranking based on ductility [Dewson, S.J., et al., 2005]

\begin{tabular}{|c|l|}
\hline Alloys & Ductility \\
\hline 617 & Excellent \\
\hline 230 & Very Good \\
\hline 556 & Good \\
\hline HX & Fair \\
\hline
\end{tabular}

The creep rupture stress for these alloys at high temperature can be associated with the ASME allowable stress. Alloy 617 exhibits the highest level of creep strength at high temperatures. At a test condition of $982^{\circ} \mathrm{C}$ and 14 $\mathrm{MPa}$, the creep rupture life is shown in Table 7.

Table 7. Candidate material ranking based on creep rupture life [Dewson, S.J., et al., 2005]

\begin{tabular}{|c|c|}
\hline Alloys & Creep Rupture Life \\
\hline 617 & $10,000 \mathrm{hrs}$ \\
\hline 556 & $7,500 \mathrm{hrs}$ \\
\hline 230 & $5,000 \mathrm{hrs}$ \\
\hline $\mathrm{HX}$ & $2,400 \mathrm{hrs}$ \\
\hline
\end{tabular}

The ideal candidate material should have high thermal conductivity and low thermal expansion, as can be seen from Figure 20 and Figure 21. Whatever material is selected thermal conductivities are relatively low and coefficients of thermal expansion significant, when the consideration is given to the operating temperature. Both of these properties impacts the selection and design criteria. 


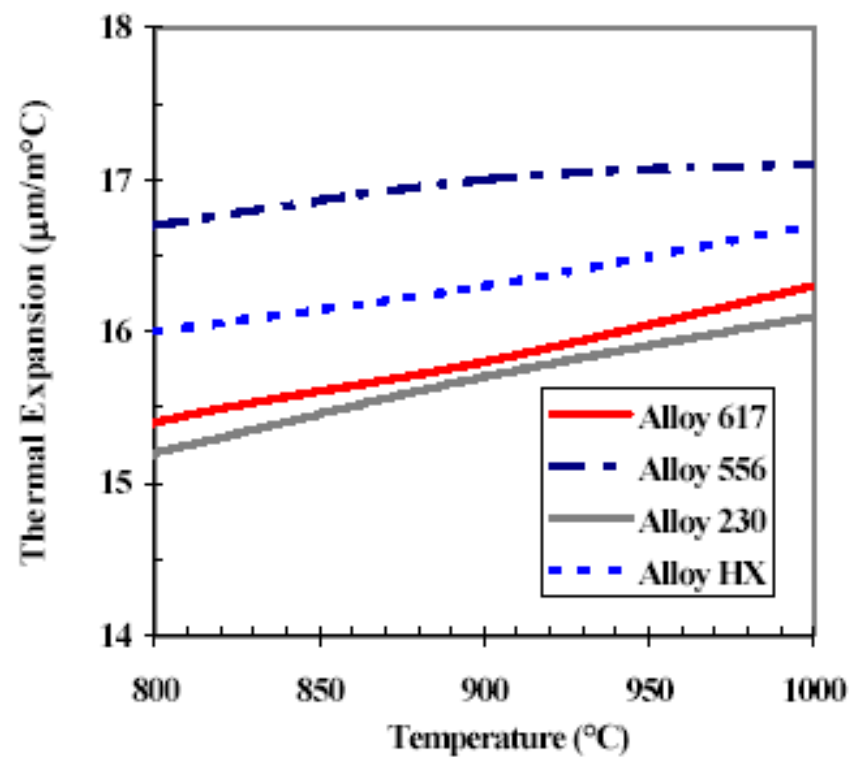

Figure 20. Thermal expansion for the various alloys at elevated temperatures [Dewson, S.J., et al., 2005]

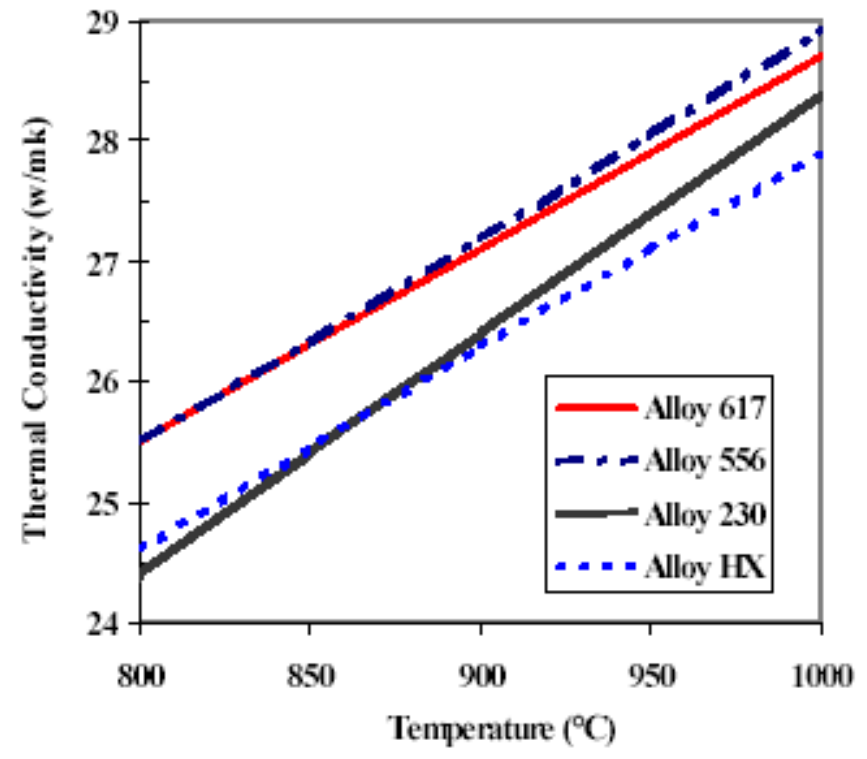

Figure 21. Thermal conductivity for the various alloys at elevated temperatures [Dewson, S.J., et al., 2005]

Relatively low thermal conductivities will reduce the efficiency of any finned structure. As a consequence heat exchangers such as the SHE and PCHE, which are considered to have all primary surface, will have an advantage over heat exchanger types that are dependent upon secondary surface, such as fins. 
Nickel based alloys generally have good nitridation resistance due to the low solubility of nitrogen in these alkali metals. Figure 22 shows nitrogen absorption after 168 hours at $648^{\circ} \mathrm{C}$ in flowing ammonia. Although the ammonia data is not directly comparable with IHX or thermosyphon environment, it demonstrates that alloy 230 has the best nitriding resistance of the alloys considered.

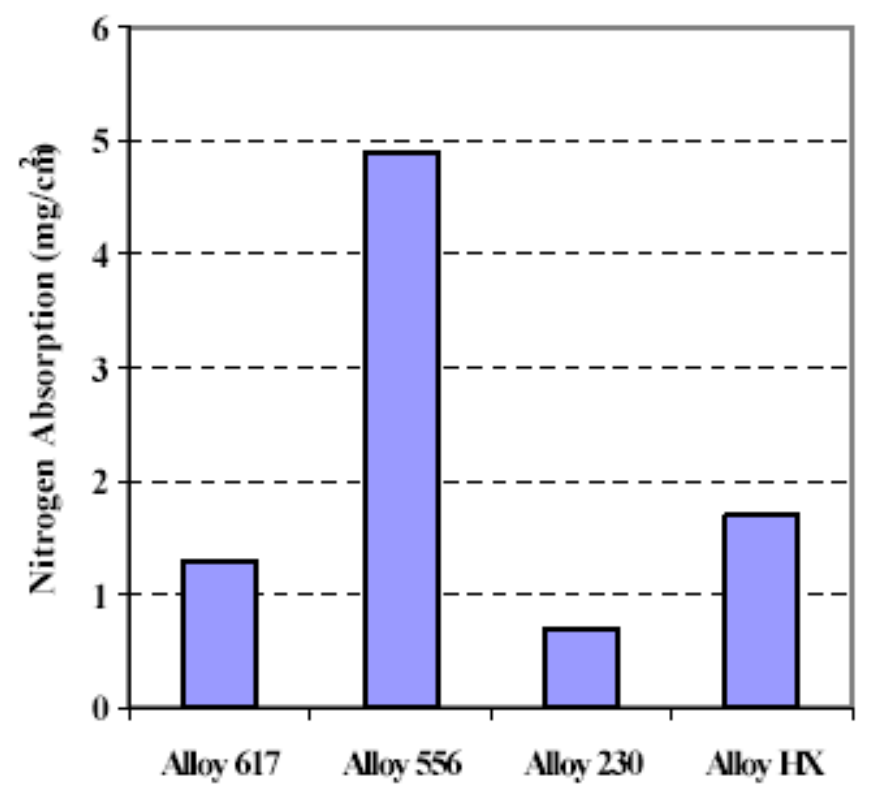

Figure 22. Comparison of Nitriding Resistance [Dewson, S.J., et al., 2005]

\section{Fabrication}

The behaviour of an alloy during fabrication activities such as forming, machining and welding can be one of the most critical factors in whether or not an alloy is chosen for the construction of thermosyphon.

Based on the overall evaluation of mechanical properties, the alloy 617 appears to be the better material for the construction of thermosyphon. This being the only available alloy that have the appropriate combination of mechanical, physical and corrosion resistance properties. 


\section{Conclusion}

The success of the next generation of nuclear reactor will depend in part upon the correct selection of the heat transport devices and high integrity compact heat exchanger, which has been discussed in this report. Out of the coolants that have been examined Li has the highest enthalpy gain, but because of its very high boiling point (exceeding the operating temperature by $550 \mathrm{~K}$ ) is discarded for this application. Therefore the best coolant for usage with enthalpy gain of almost 3.5 times compared to single phase is chosen, which is $\mathrm{Na}$.

For process heat, IHX is required to transfer heat from the NGNP to the hydrogen plant in the most efficient way possible. The IHX design requirements are governed by the allowable temperature drop between the outlet of the NGNP $\left(900^{\circ} \mathrm{C}\right.$, based on the current capabilities of NGNP), and the temperatures in the hydrogen production plant. Both PCHE design and SHE are discussed in this report. SHE have superior heat transfer characteristics, when compared with conventional Shell and Tube design and are less susceptible to fouling. Further, heat losses to surroundings are minimized because of its compact configuration. The SHE model was developed in FLUENT and was found to be in good agreement with Dittus-Boelter correlation.

The candidate materials used in the construction of thermosyphon and in the construction of compact heat exchanger will need to be available in the appropriate product forms, be weld-able and be suitable for use at temperature up to $1000^{\circ} \mathrm{C}$. Based on the overall evaluation of mechanical properties, the alloy 617 is the most suitable material for the construction of thermosyphon which is the only alloy that has the appropriate combination of mechanical, physical and corrosion resistance properties. It will be necessary to develop and qualify inspection procedures and techniques that are applicable to the materials of construction and compact heat exchanger technology. 


\section{References}

Bes, T.H., and Roetzel,W.," Thermal Theory of the Spiral Heat Exchanger," International Journal of Heat and Mass Transfer, 36, 1993

Brennan, P.J., "Heat Pipe Design Handbook", National Aeronautics and Space Administration Goddard Space Flight Center, Contract No. NAS5423406, June 1979

Bystrov, P.V., Kagan, D.N., Krechetova, G.A. and Shpilrain, E.E., "Liquid-Metal Coolants for Heat Pipes and Power Plants”, Hemisphere Publishing Corporation, 1990

Davis, C., OH., C., BARNER, R., SHERMAN, S., and WILSON, D., “Thermal-Hydraulic Analyses of Heat Transfer Fluid Requirements and Characteristics for Coupling A Hydrogen Production Plant to a HighTemperature Nuclear Reactor,” INL/EXT-05-00453, 2005

Dewson, S. J. and Grady, C., HEATRIC ${ }^{\text {TM }}$ Workshop at MIT, Cambridge, Ma, U.S.A., October 2nd, (2003)

Dewson, S.J., and Li, X., "Selection Criteria for The High Temperature Reactor Intermediate Heat Exchanger” Proceedings of ICAPP '05, Seoul, Korea, May 15-19, 2005 Paper 5333

Dostal, V., Driscoll., M.J., and Hejzlar, P., “A Supercritical Carbon Dioxide Cycle for Next Generation Nuclear Reactors," MIT-ANP-TR-100, March 2004

Fink, J.K. and Leibowitz, L., “ Thermodynamic and Transport Properties of Sodium Liquid and Vapor," ANL/RE-95/2, 1995

Gaugler, R.S. US Patent 2350348. Appl. 21 Dec, 1942. Published 6 ${ }^{\text {th }}$ June 1944

Golden, G.H., and Tokar, T.V., “Thermophysical Properties of Sodium” ANL-7323, Argonne National Laboratory Report (1967)

Gunnerson,F., Sabharwall,P., and Sherman,S., "Comparison of Sodium Thermosyphon with Convective Loop,"Proceedings of the 2007 AIChE Conference, Salt Lake City, November $4^{\text {th }}$ to $9^{\text {th }}, 2007$ 
Johnston, A.M., and Haynes, B.S., “Design Considerations For Compact Heat Exchangers”, Heatric Internal Report, (2007)

Lyon, R.N., et.al, "Liquid Metals Handbook", The Committee on the Basic Properties of Liquid Metals, Office of Naval Research, Department of Navy, $2^{\text {nd }}$ edition, June 1952

Li, X., Pierres Le, R., and Dewson, S.J., "Heat Exchangers for the Next Generation of Nuclear Reactors", Proceedings of ICAPP '06 Reno, NV USA, June 4-8, 2006, Paper 6105

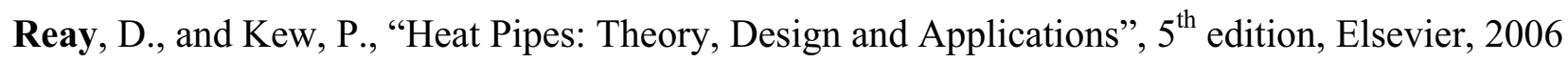

Sabharwall, P., Sherman,S., and Utgikar,V., "NGNP Process Heat Utilization: Evaporative Spiral Heat Exchanger Design," Proceedings of the 2007 AIChE Conference, Salt Lake City, November $4^{\text {th }}$ to $9^{\text {th }}, 2007$

Sabharwall, P., Sherman,S., Utgikar,V., and Gunnerson,F., “Alternate Intermediate Heat Exchanger Design for Nuclear Hydrogen Production," Proceedings of the 2007 National American Nuclear Society Conference, Boston, June $24^{\text {th }}$ to $28^{\text {th }}, 2007$

Vargaftik, N.B., Vinogradov, Y.K., and Vargin, V.S., "Handbook of Physical Properties of Liquids and Gases", Hemisphere Publications, $2^{\text {nd }}$ Edition, 1983

Zhang, N., Jiao Z., Ni Z. and Kung HC., “A Computational Method for Thermal Design of Spiral Plate Heat Exchanger", Proceedings of the 1988 National Heat Transfer Conference, ASME, Vol. 1, HTD, Houston, Texas, July 24-27, 1988 